\title{
Lmxla and Lmxlb Function Cooperatively to Regulate Proliferation, Specification, and Differentiation of Midbrain Dopaminergic Progenitors
}

\author{
Carol H. Yan, ${ }^{1 *}$ Martin Levesque, ${ }^{1 *}$ Suzanne Claxton, ${ }^{1}$ Randy L. Johnson, ${ }^{2}$ and Siew-Lan Ang ${ }^{1}$ \\ ${ }^{1}$ Department of Developmental Neurobiology, National Institute for Medical Research, The Ridgeway, London NW7 1AA, United Kingdom, and \\ ${ }^{2}$ Department of Molecular Genetics, University of Texas M. D. Anderson Cancer Centre, Houston, Texas 77030
}

\begin{abstract}
LIM homeodomain transcription factors, Lmxla and Lmxlb, are required for the development of midbrain dopaminergic (mDA) neurons. Lmxlb is required for the specification and maintenance of $\mathrm{mDA}$ neurons, primarily due to its role in isthmic organizer development that is essential for the induction of mDA neurons. Here, we conditionally deleted Lmxlb in the ventral neural tube using ShhCre and found that $L m x 1 b$ conditional mutant mouse embryos show no defect in the development and maintenance of mDA neurons. In addition, Dreher (Lmxla mutant) embryos display only a moderate reduction in the number of mDA neurons, suggesting that the related family member Lmx $1 b$ might compensate for Lmxla function. We therefore generated $L m x 1 a$ and $L m x 1 b$ double mutants. Severe loss of mDA neurons occurred in $\operatorname{Lm} x 1 a^{d r / d r} ; S h h^{C r e /+} ; \operatorname{Lm} x 1 b^{f f f}$ double mutants due to essential roles for Lmxla and Lmxlb in regulating the proliferation and neuronal commitment of mDA progenitors through the expression of Wnt1 and Ngn2, respectively. Lmxla and Lmx1b also negatively regulate Hes1 expression and consequently cell cycle exit through activation of p $27^{\text {Kip } 1}$ expression. In addition, Lmxla and Lmx1b also regulate the expression of floor plate genes such as Corin and Slit2 and specification of postmitotic mDA neurons. These defects were more severe with decreasing gene dosage of Lmxla and Lmxlb or observed only when all four copies of Lmxla and $\mathrm{Lmx} 1 \mathrm{~b}$ genes were inactivated. Together, our results demonstrate that $\mathrm{Lmx} 1 \mathrm{a}$ and $\mathrm{Lmx} 1 \mathrm{~b}$ function cooperatively to regulate proliferation, specification, and differentiation of $\mathrm{mDA}$ progenitors, including their floor plate-like properties.
\end{abstract}

\section{Introduction}

Midbrain dopaminergic ( $\mathrm{mDA}$ ) neurons have diverse roles in regulating motor and cognitive functions (Bjorklund and Lindvall, 1984). Degeneration or dysfunctions of these neurons can lead to severe neurological disorders such as Parkinson's disease (Lang and Lozano, 1998; Olanow et al., 2003). These neurons are thought to arise from progenitors in the floor plate region of the caudal diencephalon and the mesencephalon (Marin et al., 2005; Andersson et al., 2006a; Ono et al., 2007). Extrinsic signals, such as sonic hedgehog (Shh), fibroblast growth factor-8 (Fgf8), Wnt 1 , and transforming growth factor- $\beta 2$ (Tgf- $\beta 2$ ) and Tgf $\beta 3$ specify mDA progenitor identity (Hynes et al., 1997; Ye et al., 1998; Farkas et al., 2003; Prakash et al., 2006). Consequently, $\mathrm{mDA}$ progenitors are assigned a combined transcription factor

\footnotetext{
Received March 1, 2011; revised June 20, 2011; accepted July 7, 2011

Author contributions: C.H.Y., M.L., and S.-L.A. designed research; C.H.Y., M.L., and S.C. performed research; R.L.J. contributed unpublished reagents/analytic tools; C.H.Y., M.L., and S.-L.A. analyzed data; C.H.Y., M.L., and S.-L.A. wrote the paper.

This work was supported by Medical Research Council United Kingdom and by a research grant from Parkinson's United Kingdom (S.-L.A.). We thank members of the laboratory for critical reading of this manuscript, Drs. T. Perlmann and J. Ericson for sharing data prior to publication, and Dr. B. Harfe for generously providing $S h h^{\text {Cre/+ }}$ mice.

${ }^{*}$ C.H.Y. and M.L. contributed equally to this work.

Correspondence should be addressed to Siew-Lan Ang, Division of Developmental Neurobiology, National Institute for Medical Research, The Ridgeway, London NW7 1AA, UK. E-mail: sang@nimr.mrc.ac.uk.

C. H. Yan's present address: Department of Biochemistry, University of Hong Kong, Hong Kong.

DOI:10.1523/JNEUROSCI.1077-11.2011

Copyright $\odot 2011$ the authors $\quad 0270-6474 / 11 / 3112413-13 \$ 15.00 / 0$
}

code, including expression of Otx2, Foxa1, Foxa2, Lmx1a, and Lmxlb.

Otx2 is a homeodomain transcription factor required for patterning the mid-hindbrain region (Puelles et al., 2003) and specification of mDA progenitors (Omodei et al., 2008). Foxal and Foxa 2 are members of the forkhead/winged helix family of transcription factors required for development and maintenance of mDA neurons in adults (Ferri et al., 2007; Kittappa et al., 2007; Lin et al., 2009). Lmxla and Lmxlb belong to the Lmx group of LIM homeodomain transcription factors and share 64\% homology in their overall amino acid composition (Hobert and Westphal, 2000). Lmxla spontaneous mutants dreher $\left(\right.$ Lmxla $\left.{ }^{d r / d r}\right)$ exhibit a complex phenotype, including circling behavior, sterility, pigmentation, and tail abnormalities (Lyons and Wahlsten, 1988; Chizhikov et al., 2006a). Loss- and gain-of-function studies in chick embryos also demonstrate that Lmxla is an essential determinant of $\mathrm{mDA}$ neuron development (Andersson et al., 2006a). However, only $46 \%$ of $\mathrm{mDA}$ neurons are lost in $L m \times 1 a^{d r / d r}$ mutant mouse embryos, suggesting that the related family member Lmxlb may compensate for Lmxla function (Ono et al., 2007).

Loss-of-function studies demonstrate that Lmxlb regulates mid-hindbrain patterning, and consequently severe reduction of mDA neuron number is primarily due to early loss of most of the midbrain in $L m \times 1 b^{-/-}$mouse embryos (Guo et al., 2007). Lmxlb also failed to rescue the loss of mDA neurons in chick embryos with specific downregulation of Lmxla in the ventral 
midbrain using siRNAs (Andersson et al., 2006a), suggesting that Lmxlb cannot compensate for Lmxla function in the development of these neurons. In contrast, Lmxla and Lmxlb show similar roles in $\mathrm{mDA}$ neuron development in gain-of-function studies in mouse embryos (Lin et al., 2009; Nakatani et al., 2010) and in ES cells (Chung et al., 2009); however, in these experiments, Lmxlb induces Lmxla expression in $\mathrm{mDA}$ cells and a specific role of Lmxlb in mDA neuron development remains unclear.

We therefore investigated whether Lmxla and Lmxlb function cooperatively to regulate mDA neuron development using genetic studies in mice. Shh ${ }^{\mathrm{Cre} /+} ; \mathrm{L} m x 1 b^{\text {flox/flox }}$ embryos (referred to as $S h h^{C r e /+} ; \operatorname{Lm} \times 1 b^{f / f}$ ) showed no obvious phenotype in the generation of mDA neurons. In contrast, severe loss of $\mathrm{mDA}$ neurons occurred in Lmxla ${ }^{d r / d r} ; S h h^{C r e / t} ; \operatorname{Lm} x 1 b^{f / f}$ double mutants. Together, our results demonstrate cooperative roles for Lmxla and Lmxb in regulating proliferation, specification, and differentiation of mDA progenitors.

\section{Materials and Methods}

Animals. Lmx $1 a^{d r / d r}$ mutant mice (B6C3Fe-a/a-Lmx1 $a^{d r-J}$; The Jackson Laboratory), Shh ${ }^{\mathrm{Cre} /+}$ (Harfe et al., 2004), and Lmxlb floxed (Lmxlbfff) mice (Zhao et al., 2006) were genotyped as previously described (Mishima et al., 2009). All the mice were maintained in a mixed background. Conditional $L m \times 1 b$ mice were generated by intercrossing Shh ${ }^{\mathrm{Cre} /+}$ and $L m \times 1 b^{f / f}$ mouse lines. Timed mating was set up for $3 \mathrm{~h}$ between $\operatorname{Lm} \times 1 a^{d r /+} ; S_{h h} C^{C r e /+} ; \operatorname{Lm} \times 1 b^{f /+}$ males and $\operatorname{Lm} \times 1 a^{d r /+} ; \operatorname{Lm} \times 1 b^{f / f}$ females for $L m x 1 a / b$ double-mutant studies, after which the mice were separated. The embryos were staged as E0 when a vaginal plug was detected.

Tissue analysis. The procedures for whole-mount and section in situ hybridization have been described previously (Conlon and Herrmann, 1993; Schaeren-Wiemers and Gerfin-Moser, 1993). The following mouse antisense RNA probes were used: Arx (Colombo et al., 2004), Dll1 (Bettenhausen et al., 1995), Fgf8 (Crossley and Martin, 1995), Erm (Chotteau-Lelièvre et al., 1997), Lmxla (Millonig et al., 2000), Lmx1b [320 bp long over exons 4-6 of Lmx1b gene encoding for the HD (Puelles et al., 2003)], Pitx3 (Smidt et al., 1997), Hes1 (Tomita et al., 1996), Shh (Echelard et al., 1993), and Wnt1 (McMahon and Bradley, 1990). Antisense probes for Msx1, Slit2, Corin, and Nato3 were generated from cDNA templates using RT-PCR as described previously (Krawchuk and Kania, 2008). cDNA template was generated from E12.5 ventral midbrain RNA. Primer sequences are available upon request.

Immunohistochemistry on brain sections were performed as described previously (Ferri et al., 2007). Primary antibodies used in this study were as follows: rabbit anti-aromatic L-amino acid decarboxylase (AADC) (1:500; Novus Biologicals), rat anti-BrdU (1:20; AbD Serotec), rabbit anti-Cyclin D2 (1:200), rabbit anti-Nurr1 (1:200; Santa Cruz Biotechnology), rabbit anti-Isl-1/2 (K4) (1:500) (Tsuchida et al., 1994), rat anti-Ki67 (1:50; Dako), mouse anti-Ki67 (1:50; BD Biosciences Pharmingen), mouse anti-Lim1/2 (1:20), mouse anti-Nkx6.1 (1:200), mouse anti-Nkx2.2 (1:25; DSHB), rabbit anti-Lmxla (1:500; kindly provided by M. German, University of California, San Francisco, Diabetes Center, San Francisco, CA), guinea pig anti-Lmx1b (1:2000; generous gift from Drs. T. Mueller and C. Birchmeier, Max Delbruck Center of Molecular Medicine, Berlin, Germany), mouse anti-Mash1 (1:200), mouse anti-Ngn2 (1:20; kindly provided by D. Anderson, California Institute of Technology, Pasadena, CA), mouse anti-p27 (1:200), rabbit anti-Sox2 (1:200), mouse anti-Brn3a (1:5), rabbit anti-vesicular monoamine transporter (VMAT) (1:100), sheep anti-TH (1:200; Millipore), rabbit anti-TH (1:1000; Pel-Freez Biologicals), and rabbit anti-Pitx3 (1: 500; Invitrogen).

Cell counting. Quantifications of cells were performed from confocal images acquired after immunohistochemistry. For E10.5 embryos, the total number of cells was obtained by counting cells from every fourth sections at $12 \mu \mathrm{m}$ thickness and multiplying raw counts by 4 . For E12.5 embryos, cells from one-half of the sections separated at the ventral midline were counted on every sixth section at $12 \mu \mathrm{m}$ thickness, and total number of cells of the mDA region was obtained by multiplying raw counts by 12. For E18.5 data, we counted all $\mathrm{TH}+$ neurons from five matching sections of $12 \mu \mathrm{m}$ (one section every six) from wild-type, $L m \times 1 a^{d r / d r}$, and $L m \times 1 a^{d r / d r} S_{h} h^{c r e /+} L m \times 1 b^{f / f}$ embryos $(n=3$ for each genotype). The rostral-most level corresponds to mouse brain atlas at bregma $-2.78 \mathrm{~mm}$ (Allen Institute for Brain Science). At this level, part of the posterior hypothalamus and the fasciculus retroflexus are located dorsally and medially to the VTA. The posterior-most section corresponds to bregma -3.08 , where the fasciculus retroflexus forms a round bundle of fiber located ventrally to the VTA. The total number of embryos counted was 74 that were harvested from 24 litters. Quantitative data represent mean \pm SEM for cell counts of the entire midbrain. Twotailed Student's $t$ tests or ANOVA were used to determine statistical significance. ${ }^{*} p<0.05 ;{ }^{* *} p<0.01 ;{ }^{* *} p<0.001$; N.S., not significant.

In vivo proliferation assays. Pregnant females received intraperitoneal injection of BrdU (100 mg/kg; Sigma-Aldrich) $1 \mathrm{~h}$ before embryos being harvested and fixed with $4 \%$ paraformaldehyde. Sections were immunostained with rat anti-BrdU in combination with mDA cell marker (antiLmxla or anti-Lmx1b) and/or with anti-Ki67.

Quitting fraction. Twenty-four hours before harvesting embryos, pregnant females received intraperitoneal injection of BrdU $(100 \mathrm{mg} / \mathrm{kg}$; Sigma-Aldrich). Sections from E11.5 embryos were then triple stained for Ki67, BrdU, and Lmxlb. The quitting fraction is obtained by dividing the number of BrdU-labeled cells that had left the cell cycle $(\mathrm{Ki} 67-\mathrm{BrdU}+\mathrm{Lmxlb}+)$ by the number of BrdU-labeled cells that were still cycling $(\mathrm{Ki} 67+\mathrm{BrdU}+\mathrm{Lmx} 1 \mathrm{~b}+)$.

\section{Results}

Expression of Lmx1b in mDA progenitors and neurons is not required for their generation and maintenance

To study the specific effect of $L m \times 1 b$ on mDA neuron development without disrupting the isthmic organizer, the $L m x 1 b$ floxed allele (Zhao et al., 2006) was conditionally inactivated at the ventral midline by ShhCre (Harfe et al., 2004). In contrast to the conventional $L m \times 1 b$ knock-out $\left(\operatorname{Lm} \times 1 b^{-/-}\right)$mice, which die within $24 \mathrm{~h}$ of birth (Chen et al., 1998), $L m \times 1 b$ conditional knock-out $\left(\mathrm{Shh}^{\mathrm{Cre} /+} ; \operatorname{Lm} \mathrm{m} 1 b^{f / f}\right)$ mice were born at the expected Mendelian frequency, were fertile and morphologically indistinguishable from their wild-type littermates, survived to adulthood, and did not show any behavioral defects at least until 18 months of age (data not shown).

Cre expressed from the Shh promoter is efficient in deleting $L m \times 1 b$ in the ventral midbrain at E9.5, E10.5, and E12.5 (Fig. $1 A, B, E, F, I, J)$, in agreement with earlier studies using $S h h^{\mathrm{Cre} /+}$ mice to delete other genes in the ventral midbrain (Joksimovic et al., 2009a,b). However, in the caudal-most region of the midbrain, $L m x 1 b$ was not deleted in a small number of mDA cells (Fig. $1 C, D, G, H, K, L)$. For this reason, all analyses shown in this paper do not include the caudal-most part of the midbrain and correspond to sections where deletion of Lmx1b is complete. The morphology of the isthmus and the expression of both Fgf8 and Erm, a downstream target of Fgf signaling, appeared normal in $\mathrm{Shh}^{\mathrm{Cre} /+} ; \mathrm{Lm} \times 1 b^{f / f}$ embryos at E10.5 (Fig. $1 \mathrm{M}-\mathrm{P}$ ), suggesting that Fgf signaling from the isthmic organizer is not disrupted in Lmx $1 b$ conditional mutants.

Analyses of $\mathrm{TH}$ expression by immunohistochemistry revealed no significant changes in the number of $\mathrm{TH}+\mathrm{mDA}$ neurons in $\mathrm{Shh}^{\mathrm{Cre} /+} ; \mathrm{Lm} \times 1 b^{f / f}(123.7 \pm 8.6 \%)$ and wild-type (100\%) embryos at E12.5 (Fig. $2 A-C$; Student's two-tailed $t$ test, $p=$ 0.11 ), in contrast to the strong reduction of $\mathrm{TH}+\mathrm{mDA}$ neurons in $L m \times 1 b^{-/-}$embryos (Smidt et al., 2000). Moreover, there was no difference in the expression of Lmxla and Lmxlb in mDA progenitors of $S_{h} h^{C r e /+} ; L m x 1 b^{f / f}$ embryos (Fig. $2 A, B, D, H$, respectively). Importantly, late postmitotic markers Pitx3, AADC, $\mathrm{TH}, \mathrm{VMAT}$ were still normally expressed in the mature neurons 


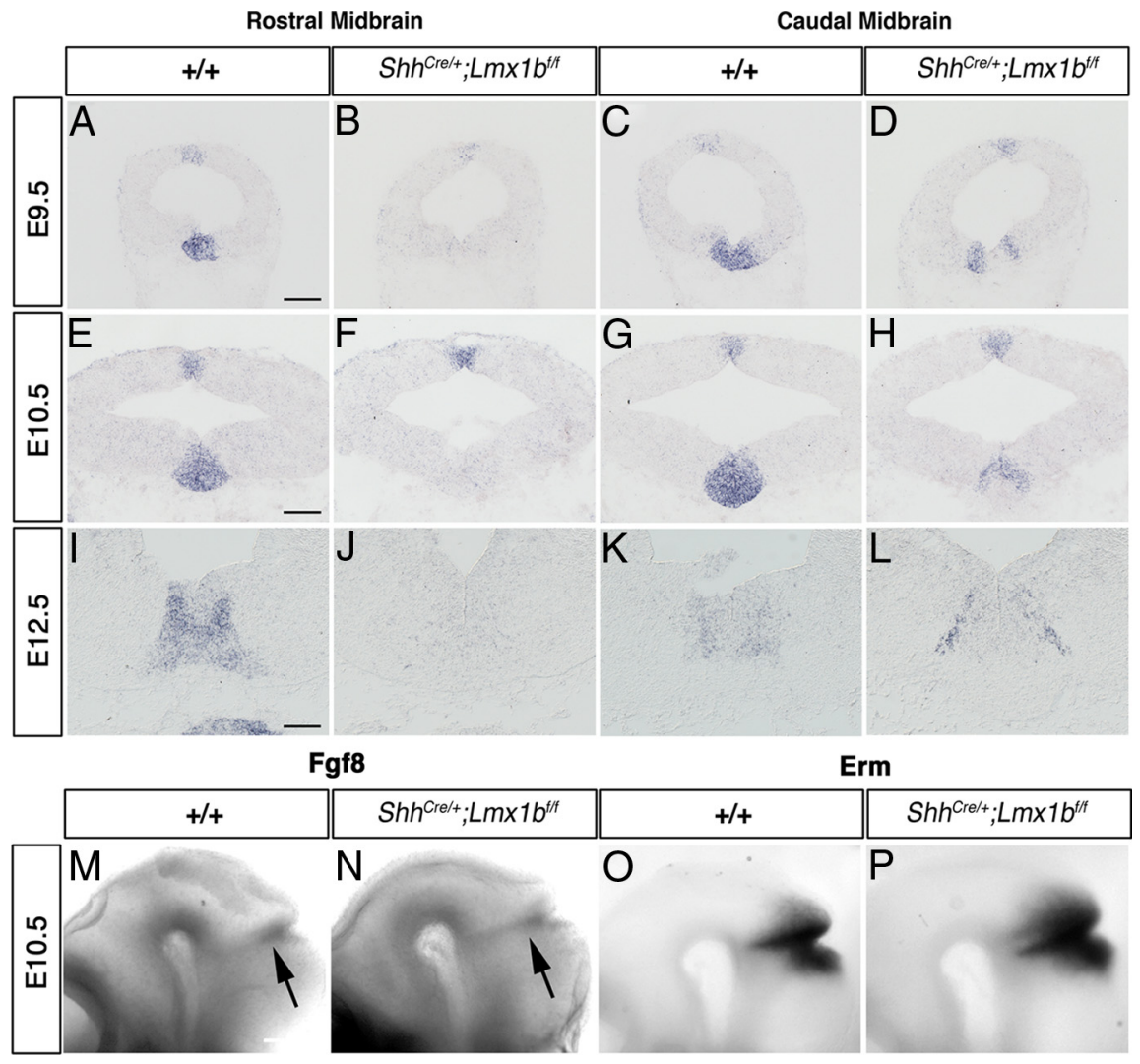

Figure 1. $L m x 1 b$ is deleted in the majority of the $m D A$ domain before the generation of mDA neurons. $A, C, E, G, I, K, L m x 1 b$ transcripts were detected in the ventral midline of wild-type embryos in the midbrain. $B, D, F, H, J, L, L m x 1 b$ transcripts were only detected as two lateral stripes in the caudal midbrain and was undetectable in the rostral midbrain of $\mathrm{Shh}^{\mathrm{Cr} /{ }^{+}} ; \mathrm{Lmx} 1 \mathrm{~b}^{\mathrm{f} / \mathrm{ff}}$ embryos at E9.5, E10.5, and E12.5. Fgf signaling from the isthmus organizer is not disrupted in $\mathrm{Shh}^{\mathrm{Cre} /+}, \mathrm{Lm} \times 1 b^{\mathrm{fff}}$ embryos as shown by whole-mount in situ hybridization for Fgf8 and for its downstream target Erm at E10.5 (M-P). The arrow in $\boldsymbol{M}$ and $\boldsymbol{N}$ indicates the position of the isthmus. Scale bars, $100 \mu \mathrm{m}$.

of $S h h^{C r e /+} ; L m x 1 b^{f / f}$ embryos (Fig. $\left.2 E-G, I, K\right)$. These results indicate that Lmxlb transcriptional activity in the mDA domain is neither required for the development of $\mathrm{mDA}$ neurons nor for the expression of mature dopaminergic markers from E9.5 onward. Furthermore, previous studies have shown that $\mathrm{TH}+$ neurons fail to survive beyond E16.0 in $L m \times 1 b^{-/-}$embryos (Smidt et al., 2000). In contrast, there was no obvious reduction in the $\mathrm{TH}+\mathrm{mDA}$ neurons of $S h h^{\mathrm{Cre} /+} ; \operatorname{Lm} x 1 b^{f / f}$ embryos at E18.5 (data not shown). Therefore, $\mathrm{Lmx} 1 \mathrm{~b}$ is also not required for the survival of mDA neurons during development from E9.5 onwards.

\section{Functional cooperation between Lmxla and Lmx1b in mDA neuron development}

Neither the spontaneous Lmxla mutants dreher $\left(\operatorname{Lm} x 1 a^{d r / d r}\right)$ nor $\mathrm{Shh}^{\mathrm{Cre} /+} ; \mathrm{Lm} \times 1 b^{f / f}$ mutants display the severe defects in $\mathrm{mDA}$ neuron development observed in siRNA knockdown study of Lmxla in chick embryos (Andersson et al., 2006a). Furthermore, single mutants of either $L m x 1 a$ or $L m \times 1 b$ continue to express Lmx1b (Ono et al., 2007) and Lmxla (Fig. 2A,B), respectively. We therefore investigated functional redundancy between Lmxla and Lmxlb by studying the phenotype of double mutants of $L m x 1 a$ and $L m \times 1 b$. Double homozygous $L m \times 1 a^{d r / d r} ; S_{h h^{C r e /+}}$; $L m \times 1 b^{f / f}$ mice rarely survived after birth. Only 2 of 206 animals that survived to weaning were homozygous for both $L m \times 1 a$ and $L m \times 1 b$ mutant alleles. Mice carrying a single wild-type allele of $L m x 1 a$ $\left(\operatorname{Lm} \times 1 a^{d r /+} ; S_{h} h^{C r e /+} ; \operatorname{Lm} \times 1 b^{f / f}\right)$ survived to adulthood, did not display any morphological and behavioral defects, and were fertile. Mice carrying a single wild-type allele of $L m \times 1 b$ $\left(\operatorname{Lm} \times 1 a^{d r / d r} ; S h h^{C r e /+} ; \operatorname{Lm} \times 1 b^{f /+}\right)$ showed the classical dreher phenotype of head-tossing, ataxia, circulating behavior, and abdominal white patches of fur (Lyons and Wahlsten, 1988).

The development of $\mathrm{mDA}$ progenitors (Lmxla+Ki67+), immature (Nurr1+TH-) and mature (Nurr1+TH+) neurons was then assessed and quantified in the whole midbrain region of $L m \times 1 a / b$ single and compound mutants at E12.5 (Fig. 3). Both the $L m \times 1 a^{d r}$ and $L m \times 1 b^{f l o x}$ alleles generate truncated proteins that are still recognized by the Lmxla and Lmxlb specific antibodies. However, both alleles are very likely null alleles based on the similar brain phenotypes of homozygous $L m x 1 a^{d r / d r}$ (Chizhikov et al., 2006b) and Wnt1cre/+;Lmxlbflox/flox (Guo et al., 2007) embryos, when compared with the phenotypes of embryos that are homozygous for Lmxla-null and LmxIb-null alleles, respectively. The whole mDA population, including progenitors, immature neurons, and mature neurons, was significantly reduced in $L m \times 1 a^{d r / d r}(74.8 \pm 1.6 \%)$, $\mathrm{Lm}_{1} 1 a^{\mathrm{dr} / \mathrm{dr}} ; \mathrm{Shh}^{\mathrm{Cre} /+} ; \mathrm{Lm} \times 1 b^{f /+}(45.2 \pm$ $1.9 \%)$, and $L m \times 1 a^{d r / d r} ; S_{S h}{ }^{C r e /+} ; \operatorname{Lm} x 1 b^{f / f}$ $(8.0 \pm 0.6 \%)$ embryos, when compared with wild-type embryos. There was a proportionate decrease in both $\mathrm{mDA}$ progenitors and neurons by reducing the $L m \times 1 b$ gene dosage on $L m \times 1 a^{d r / d r}$ background (Fig. $3 A-K)$. Confirmation of the decrease numbers of each $\mathrm{mDA}$ population was verified by additional markers [i.e., Lmx1b+Sox $2+$ for progenitors (see Fig. $7 F-J$ ) and Lmx1b+Sox2 - for immature neurons (see Fig. $7 F-J$ ) and Pitx3 + (Fig. $3 L-P$ ) for mature neurons]. On the contrary, the loss of Lmxlb in $\mathrm{Shh}^{\mathrm{Cre} /{ }^{+}} ; \mathrm{Lm} \mathrm{m} \mathbf{1} \mathrm{b}^{f / f}$ embryos led to no significant change in the whole $\mathrm{mDA}$ population $(114.9 \pm 4.8 \%)$ relative to the numbers present in wild-type embryos. Removing one copy of $L m x 1 a$ from $S h h^{C r e /+} ; L m x 1 b^{f / f}$ embryos only resulted in a mild reduction in mDA neuron number $(94.4 \pm 3.4 \%)$. These results indicate that Lmxla plays a key role in $\mathrm{mDA}$ neuron development, and that Lmxlb can partially compensate for the loss of Lmxla in mDA neuron development.

The reduction in the number of mature Nurr1 $+\mathrm{TH}+\mathrm{Pitx} 3+$ mDA neurons in $L m \times 1 a^{d r / d r}, \operatorname{Lm} x 1 a^{d r / d r} ; S_{S h}^{C r e /+} ; L m \times 1 b^{f /+}$, and $L m \times 1 a^{d r / d r} ; S_{h h}{ }^{C r e /+} ; L m \times 1 b^{f / f}$ embryos persisted into E18.5 (Fig. 4 ), demonstrating an essential role for Lmxla and Lmxlb in the generation of mDA neurons and that the loss of these neurons is not due to a developmental delay. Quantification of the mature mDA neurons $(\mathrm{TH}+)$ revealed that $L m \times 1 a^{d r / d r} ; S h h^{C r e /+} ; L m \times 1 b^{f / f}$ mutant embryos contained only $2.7 \pm 0.5 \%$ of the number in control embryos.

\section{$\mathrm{Lmxla/b}$ cooperatively regulate the proliferation of $\mathrm{mDA}$ progenitors}

The mDA progenitor populations were significantly reduced in $L m \times 1 a^{d r / d r}, L m \times 1 a^{d r / d r} ; S_{h} h^{C r e /+} ; L m \times 1 b^{f /+}$, and $L m x 1 a^{d r / d r} ; S_{h} h^{C r e /+}$; $L m \times 1 b^{f / f}$ double mutant embryos to $86.6 \pm 1.8,64.3 \pm 3.1$, and $14.6 \pm 2.6 \%$, respectively, of the wild-type level at E12.5. We deter- 
mined whether the reduction in mDA progenitor number is due to a proliferation defect or cell death. Short pulse $(1 \mathrm{~h})$ BrdU incorporation assays indicated a severe proliferation defect in $\mathrm{Lm} \times 1 a^{d r / d r}$;Shh ${ }^{\mathrm{Cre} /+}$; Lmxl $b^{f / f}$ mutants at E10.5 (Fig. 5). The mDA progenitors in active cell cycle $(\mathrm{Lmxla}+\mathrm{Ki67}+)$ (Fig. 5A-E, $\left.A^{\prime}-E^{\prime}\right)$, and $\mathrm{mDA}$ progenitors in S-phase of the cell cycle $(\mathrm{Lmxla}+\mathrm{BrdU}+)($ Fig. $5 \mathrm{~F}-J)$, were quantified at E10.5 (Fig. 5K). The percentage of cells in S-phase in $L m \times 1 a^{d r / d r}(48.4 \pm 1.1 \%)$, $L m \times 1 a^{d r / d r} ; S h^{C r e /+} ; L m \times 1 b^{f /+}(46.6 \pm 0.1 \%)$, and $L m \times 1 a^{d r / d r} ; S h h^{C r e /+} ; L m \times 1 b^{f / f}$ double mutants $(39.4 \pm 2.9 \%)$ was statistically different from wild-type embryos (55.0 $\pm 1 \%$ ) at E10.5, respectively. In contrast, there was no increase in the levels of apoptosis in any of the $L m \times 1 a / b$ single and double mutants at both E10.5 and E12.5, demonstrated by phosphorylatedCaspase 3 immunohistochemistry (Fig. $5 L-P$ ) (data not shown). These results indicate that the reduction in $\mathrm{mDA}$ progenitor numbers is a consequence of proliferation defects, but not attributed to apoptosis.

To better understand the deficiencies in proliferation, genes involved in the regulation of cell cycle were analyzed (Fig. 6). Cyclin D2, a cell cycle activator protein, was strongly downregulated in the medial region of the $\mathrm{mDA}$ progenitor domain of Lm $x 1 a^{d r / d r} ; S_{h} h^{C r e /+} ; L m \times 1 b^{f / f}$ double mutants (Fig. 6D, K). Quantitative analyses showed that the number of Cyclin D2+ mDA progenitors was significantly decreased in $L m x 1 a^{d r / d r}$ (Fig. 6B,K), and there was a proportionately further decrease in this number by reducing the $L m \times 1 b$ gene dosage on $L m \times 1 a^{d r / d r}$ background (Fig. $6 C, K$ ). In contrast, there was no significant difference in the number of Cyclin D2 + mDA progenitors in Shh ${ }^{\text {Crel }}$ $+; L m \times 1 b^{f / f}$ embryos (Fig. 6E,K). We also found that the expression of cyclin-dependent kinase inhibitor $\mathrm{p} 27^{\mathrm{Kip} 1}$, which regulates cell cycle exit, was elevated in the medial mDA progenitor domain of $L m \times 1 a^{d r / d r} ; S h h^{C r e /+} ; L m \times 1 b^{f / f}$ mutants (Fig. 6I) but was normally expressed in all other mutant embryos (Fig. $6 \mathrm{~F}-\mathrm{H}, \mathrm{J})$. We therefore investigated whether the decrease of $\mathrm{mDA}$ progenitors could also be contributed by an increased number of mDA progenitors exiting the cell cycle. The quitting fraction (Qf) (i.e., percentage of cycling progenitors quitting the cell cycle within $24 \mathrm{~h}$ of BrdU administration at E10.5) was calculated by measuring the fraction of $\mathrm{Lmxlb}^{+} \mathrm{BrdU}^{+}$cells that were $\mathrm{KI}_{67}^{-}$. We found that the Qf was increased only in $L m \times 1 a^{d r / d r} ; S h h^{C r e /+} ; L m \times 1 b^{f / f}$ mutant embryos (Fig. $6 \mathrm{~L}$ ). These data suggest that the reduced number of $\mathrm{mDA}$ progenitors is caused by decrease in cell proliferation and increase in cell cycle exit of these progenitors.

We next examined the expression of Wntl that has been implicated in regulating cell proliferation and differentiation of mDA progenitors (Castelo-Branco et al., 2004; Panhuysen et al., 2004; Tang et al., 2009, 2010). Wnt1 expression was specifically lost in lateral $\mathrm{mDA}$ progenitors but not in the roof plate of $L m \times 1 a^{d r / d r} ; S h h^{C r e /+} ; L m x 1 b^{f / f}$ mutants, while it is normally expressed in both brain regions of all other mutant and wild-type embryos (Fig. 6M-Q) at E10.5. This result demonstrates that $L m \times 1 a / b$ specifically and redundantly regulate $W n t 1$ expression in the lateral mDA domain. Together, our results demonstrate that $L m x 1 \mathrm{a} / \mathrm{b}$ are required cooperatively for the proliferation of mDA progenitors, where Lmxla plays a more important role during this process. Lmxla/b likely control the proliferation of $\mathrm{mDA}$ progenitors by regulating the expression of Wnt 1 and key cell cycle proteins Cyclin D2 and p2 $7^{\mathrm{Kip} 1}$, which in turn control the progression of the cell cycle.

\section{Changes in the specification of mDA progenitors in $L m x 1 a^{d r / d r}$;}

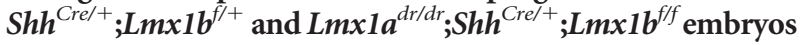
We next determined whether specification of $\mathrm{mDA}$ progenitors was also affected in $L m \times 1 a$ and $L m \times 1 b$ single and double mutants. The expression of Msx1 appeared reduced and lost in mDA progenitors of $\operatorname{Lm} \times 1 a^{d r / d r} ; S_{h} h^{C r e /+} ; L m \times 1 b^{f /+}$ (Fig. 7C) and Lmx $1 a^{d r / d r} ; S_{h} h^{C r e /+} ; L m x 1 b^{f / f}$ embryos (Fig. 7D), respectively, at E12.5, but was not affected in $L m x 1 a$ and $L m x 1 b$ single mutants when compared with wild-type embryos (Fig. $7 A, B, E$ ). Furthermore, the expression of Lmxlb in the mDA progenitors failed to be downregulated in the $L m x 1 a / b$ double mutants at E12.5 (Fig. $7 F-J$ ). Lack of downregulation of Lmxlb might indicate a delay in these cells; however, this is unlikely to be the case since downregulation of $\mathrm{En} 1$ expression in the $\mathrm{mDA}$ progenitor region of 
A

Progenitors: Lmx1a+ Ki67+

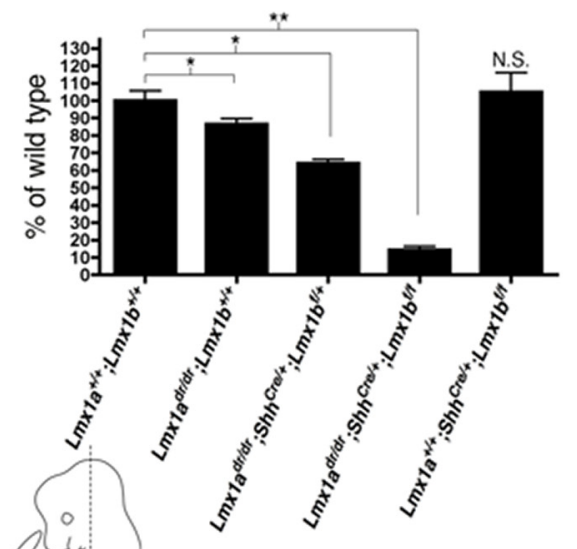

Immature neurons: Nurr1+ TH-

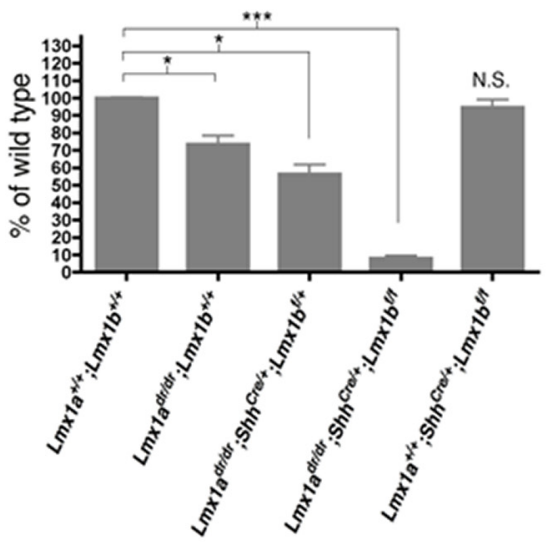

Mature neurons: Nurr1+ $\mathrm{TH}+$

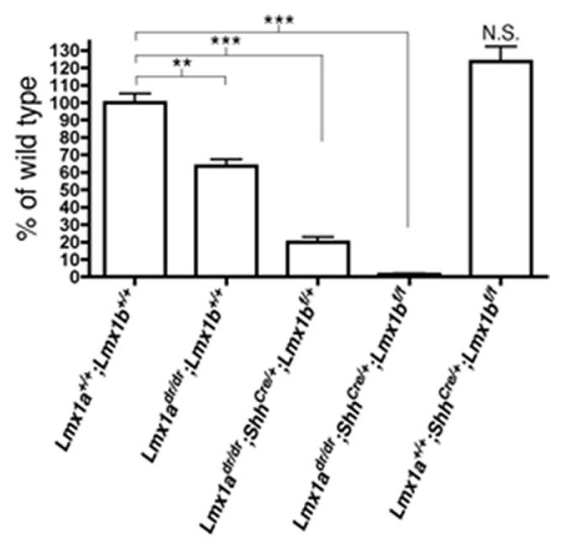

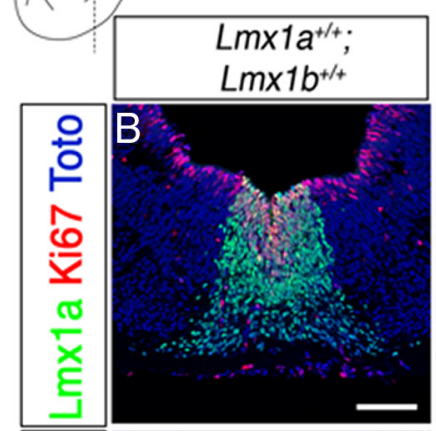
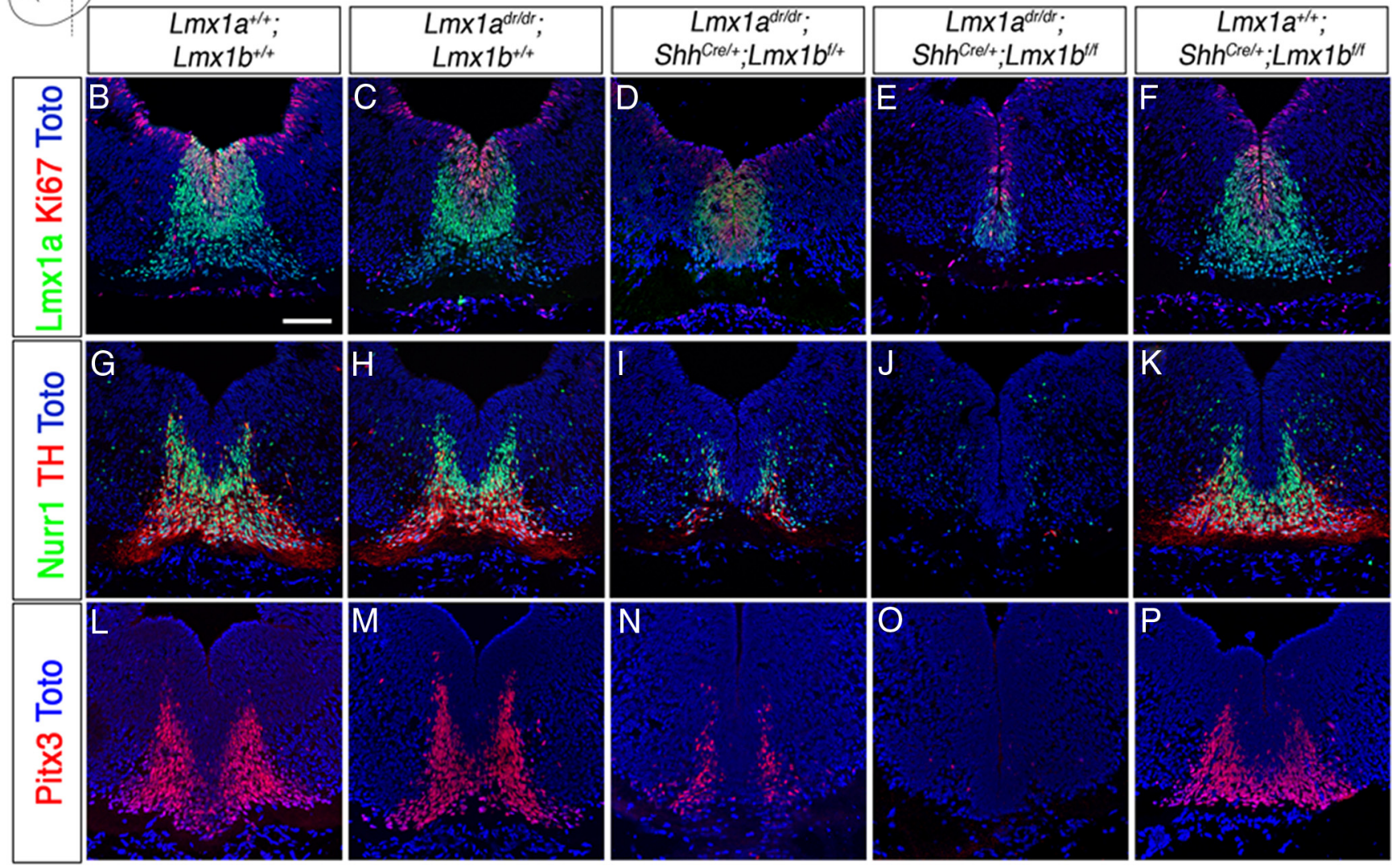

Figure 3. Lmx1a and $\operatorname{Lmx} 1 \mathrm{~b}$ cooperatively regulate $m D A$ neurons development. $\boldsymbol{A}$, Quantification of mDA progenitors $(\boldsymbol{B}-\boldsymbol{F}, \mathrm{Lmx} 1 \mathrm{a}+\mathrm{Ki} 67+)$, and immature $(\boldsymbol{G}-\boldsymbol{K}$, Nurr1 $+\mathrm{TH}-)$ and mature $(\mathbf{G}-\boldsymbol{K}, \mathrm{Nurr} 1+\mathrm{TH}+)$ neurons in the whole midbrain region of $L m \times 1 a / b$ single and compound mutants at E12.5. The expression of the specific mDA neuron marker Pitx 3 is shown in $\boldsymbol{L}-\boldsymbol{P}$. The dashed line in the schematic embryo indicates where the sections are taken from in the rostrocaudal axis. ${ }^{*} p<0.05 ;{ }^{* *} p<0.01 ;{ }^{* * *} p<0.001 ;$ N.S., not significant. Error bars indicate SEM. Scale bar, $100 \mu \mathrm{m}$.

$\operatorname{Lm} \times 1 a^{d r / d r} ; S_{h h}^{C r e /+} ; \operatorname{Lm} x 1 b^{f / f}$ double mutants occurred normally as in wild-type embryos between E10.5 and E12.5 (data not shown). In addition, Sox2 expression was still normally expressed in these progenitors in control and all mutant embryos (Fig. $7 F-I$ ), confirming the progenitor identity of these cells. Since Lmxla/b has previously been suggested to inhibit Nkx6.1 expression via Msx1 (Andersson et al., 2006a), we also examined whether Nkx6.1 expression was ectopically expressed in mDA progenitors in the absence of Lmxla/b. Expression of Nkx6.1 in all mutant embryos was similar to the wild-type pattern (Fig. $7 \mathrm{~K}-\mathrm{O}$ ). Together, these results indicate that the reduced population of mDA progenitors in $L m x 1 a / b$ double mutants are not fully specified since these cells fail to initiate and downregulate Msxl and Lmxlb expression, respectively.

mDA progenitors also express floor plate markers such as Arx (Kitamura et al., 1997), Corin (Ono et al., 2007), and Slit2 (Dugan et al., 2011). While Arx expression was not changed (Fig. $8 A-E$ ), Corin (Fig. $8 F-J$ ) and Slit2 (Fig. $8 \mathrm{~K}-\mathrm{O}$ ) expression were severely reduced in the midbrain of $L m \times 1 a^{d r / d r} ; S_{h h^{C r e /+}} ; L m \times 1 b^{f / f}$ mutants at E10.5 (data not shown) and at E12.5. Shh expression in floor plate/mDA progenitors is distinctly weaker than in basal progenitors in the ventral midbrain of wild-type embryos at E12.5. In contrast, expression of Shh in the floor plate and basal 


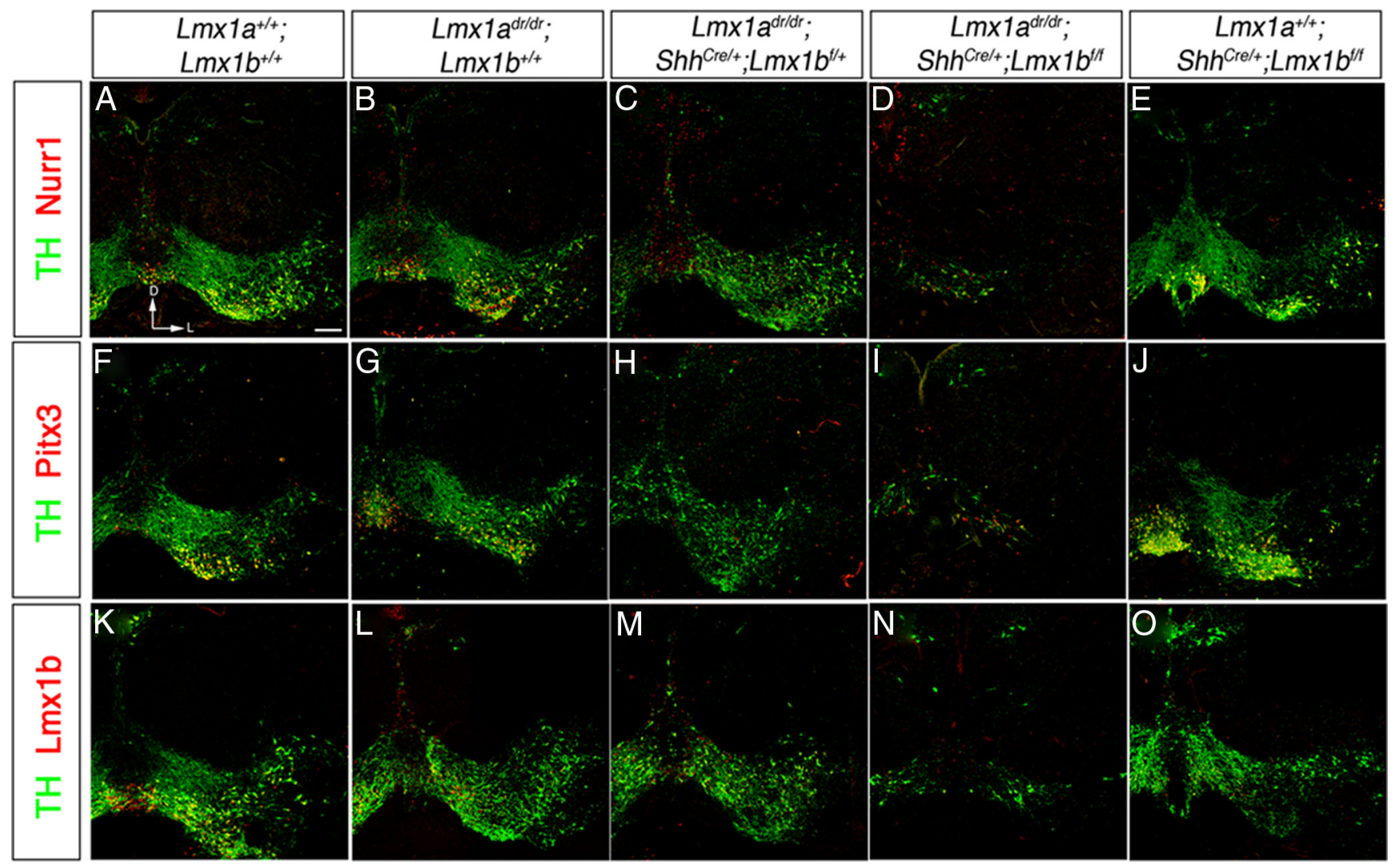

Figure 4. Loss and incomplete differentiation of mDA neurons occurs in the ventral midbrain of $L m x 1 a / b$ double homozygous mutant embryos at E18.5. Expression of mature $m D A$ neuron markers TH in combination with Nurr1 $(\boldsymbol{A}-\boldsymbol{E})$, Pitx3 $(\boldsymbol{F}-\boldsymbol{J})$, and $\operatorname{Lmx} 1 \mathrm{~b}(\boldsymbol{K}-\mathbf{0})$ in $E 18.5$ middle midbrain coronal sections from $L m \times 1 a / b$ single and compound mutants. The few remaining TH+, Nurr1 $+(\boldsymbol{D}), \mathrm{TH}+, \mathrm{Pitx} 3+(\boldsymbol{I})$, or TH,$+ \mathrm{Lmx} 1 \mathrm{~b}+(\boldsymbol{N}) \mathrm{mDA}$ neurons in $L m \times 1 \mathrm{a} / \mathrm{b}$ double mutants may be generated from caudal progenitors that did not undergo deletion of $\mathrm{Lmx} 1 \mathrm{~b}$. $S \mathrm{Cal}$ le bars, 100 $\mu \mathrm{m} . \mathrm{D}$, Dorsal; L, lateral.

region appears uniform in $L m x 1 a^{d r / d r} ; S_{h} h^{C r e /+} ; L m \times 1 b^{f / f}$ mutant embryos, while expression in other mutant embryos was similar to wild-type embryos (Fig. 8Q-T) at E12.5. Together, these results indicate that $\mathrm{Lmxla} / \mathrm{b}$ also has a role in regulating the floor plate properties in mDA progenitors.

\section{Lmxla/b regulate neurogenesis of mDA neurons}

$\mathrm{Ngn} 2$ is the major proneural factor required for neurogenesis of mDA progenitors (Andersson et al., 2006a,b; Kele et al., 2006). Lmxla has previously been shown to regulate neurogenesis by activating Msx1, which in turn induces the bHLH transcription factor Ngn2 in experiments using chick embryos and mouse mutants (Andersson et al., 2006a). Consistent with these data, Ngn2 expression was also reduced in $\operatorname{Lmx} 1 a^{d r / d r}$ mouse embryos at E11.5 (Ono et al., 2007). We therefore analyzed the expression of Ngn2 in Lmxla and/or Lmx1b single and double mutants. Ngn2 expression in mDA region was decreased in $L m \times 1 a^{d r / d r} ; S_{h} h^{C r e /+}$; $L m \times 1 b^{f /+}$ and $L m \times 1 a^{d r / d r} ; S h h^{C r e+} ; L m x 1 b^{f / f}$ embryos (Fig. 9A-E) at E12.5. As the number of $\mathrm{mDA}$ progenitors was reduced in the mutants, the number of Lmx1a+Ngn2 + cells was normalized to Lmxla + Ki67 + mDA progenitors to study the specific effect of Lmxla/b on neurogenesis. The percentage of Lmxla $+\mathrm{Ngn} 2+$ cells was reduced in $L m \times 1 a^{d r / d r} ; S_{h} h^{C r e /+} ; L m \times 1 b^{f /+}$ and $L m \times 1 a^{d r / d r}$; $\mathrm{Shh}^{\mathrm{Cre} /+} ; \mathrm{Lm} \times 1 b^{f / f}$ embryos, thus confirming neurogenesis defects in these embryos (Fig. $9 \mathrm{~K}$ ). In contrast, there was no significant loss of Ngn2 expression in $L m x 1 a^{d r / d r}$ after normalization, suggesting that expression of Ngn2 that is reduced in mDA progenitors of $L m \times 1 a^{d r / d r}$ mutant embryos at E11.5 (Ono et al., 2007) is recovered in these embryos by E12.5. To further confirm the defects in neurogenesis, expression of Delta-like 1 (Dll1), which is a direct downstream target of Ngn2, was studied at E12.5. The expression of Dll1 (Fig. $9 L-P$ ) was reduced in the same manner as Ngn2 in Lmx1a/b compound mutants. Thus, the neurogenesis defect in Lmxla/b mutants is correlated to the loss of Ngn2 expression.

Another proneural gene Mash1 (Ascl1) can partially compensate for the loss of $\mathrm{Ngn} 2$ in the differentiation of mDA neurons, although it is not required for the differentiation of the $\mathrm{mDA}$ progenitor cells in the presence of Ngn2 (Kele et al., 2006). The expression of Mash1 was reduced in the same manner as Ngn2 in $L m \times 1 a / b$ mutants (Fig. $9 F-J$ ). Since Mash1 expression in the mDA progenitors is reduced in $N g n 2^{-/-}$embryos (Kele et al., 2006), it is not possible to dissociate whether this reduction in Mash1 is a direct effect of $L m \times 1 a / b$.

A third bHLH gene, Nato3 (Ferd31), also contributes to neurogenic activity of $\mathrm{mDA}$ progenitors, in part through repression of Hes1, which negatively regulates Ngn2 expression (Nakatani et al., 2010). We therefore examined the status of Nato3 and Hes 1 expression in $L m x 1 a / b$ mutants. Interestingly, while expression of Nato3 appears unchanged (Fig. 9Q-U), Hes 1 expression was marginally and strongly detected in $\mathrm{mDA}$ progenitors of Lmx $1 a^{d r / d r} ; S_{S h}{ }^{C r e /+} ; L m \times 1 b^{f /+}$ (Fig. 9X) and Lmx1a $a^{d r / d r} ; S_{S h}{ }^{C r e /+}$; $L m \times 1 b^{f / f}$ embryos (Fig. 9Y), respectively. These results indicate that Lmxla/b repress Hes1 expression, independently of Nato3. Ectopic Hes1 likely leads to the downregulation of Ngn2 expression in mDA progenitors of both $L m \times 1 a^{d r / d r} ; S_{h} h^{C r e /+} ; L m \times 1 b^{f /+}$ and $L m \times 1 a^{d r / d r} ; S h h^{C r e /+} ; L m \times 1 b^{f / f}$ embryos, since repression of 

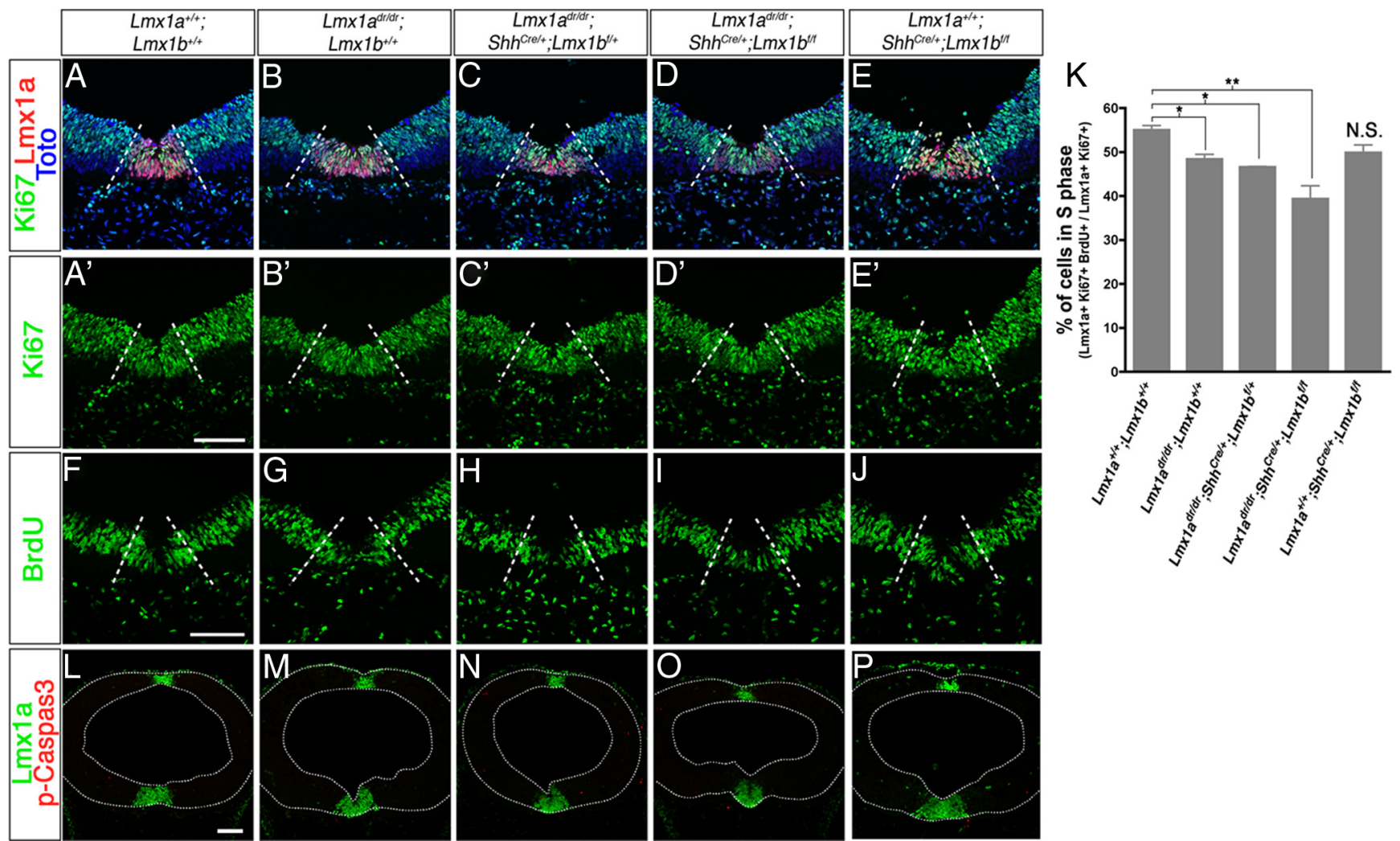

Figure 5. Lmx1a/b are required for the proliferation of $\mathrm{mDA}$ progenitors in a gene dosage-dependent manner. Proliferation index is measured in Lmx1a/b single and compound mutants by quantification of S-phase progenitors (BrdU +/Ki67+) in the Lmx1a + domain of whole midbrain and caudal diencephalon at E10.5 $(\boldsymbol{K}) . \boldsymbol{A}-\boldsymbol{E}$, mDA progenitors in active cell cycle expressed both Lmx1a and Ki67. $\mathbf{F}-\boldsymbol{J}, \mathrm{mDA}$ progenitor cells in S-phase of the cell cycle are double positive for Lmx1a and BrdU. Lmx1a + region is demarcated by dotted lines. $\boldsymbol{L}-\boldsymbol{P}$, No change in apoptosis as measured by phosphorylated Caspase 3 staining. The dotted lines indicate the outline of the neural tube. ${ }^{*} p<0.05$; ${ }^{* *} p<0.01$; N.S., not significant. Error bars indicate SEM. Scale bars, $100 \mu \mathrm{m}$.

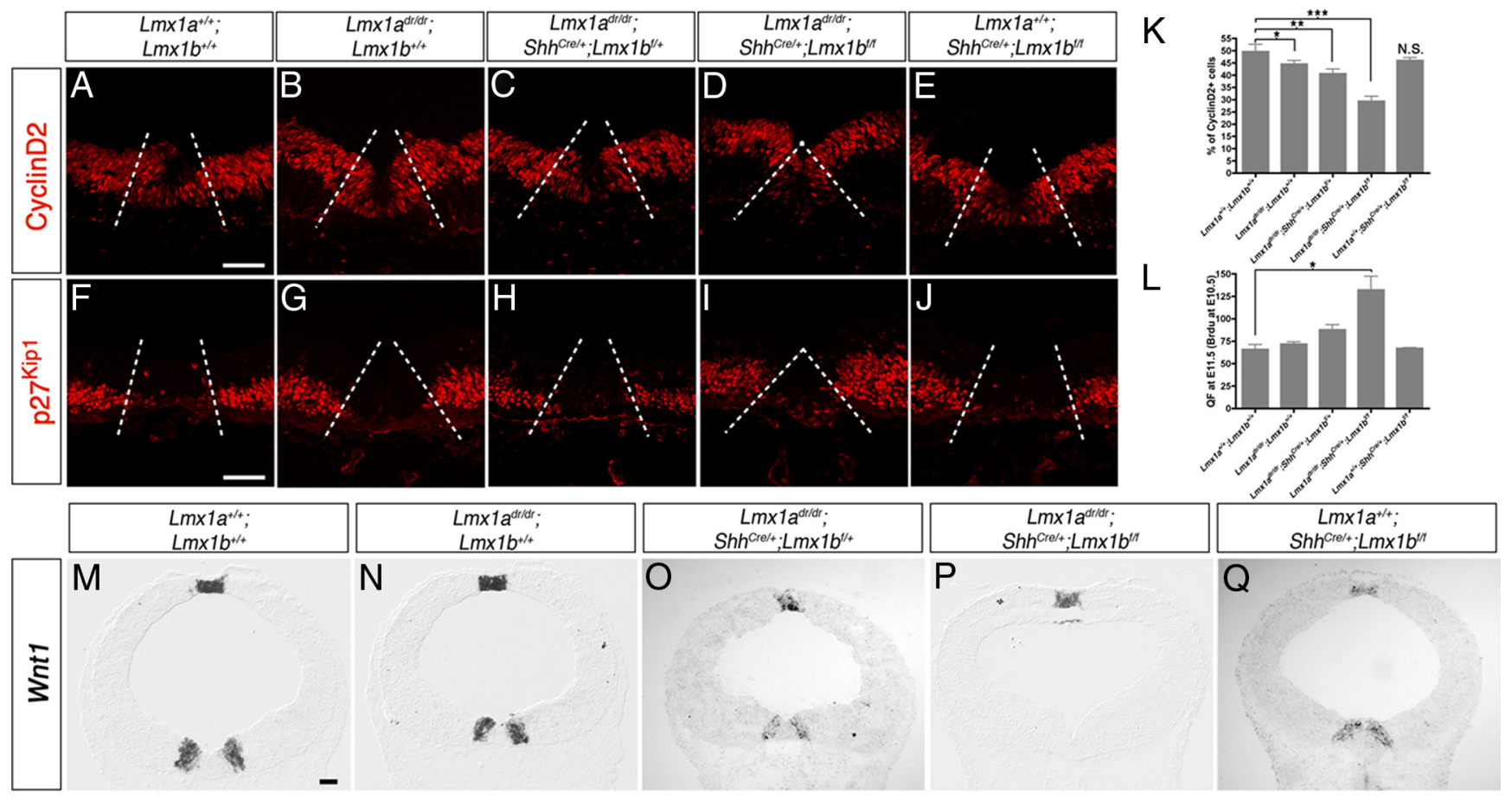

Figure 6. Cell cycle progression of $m D A$ progenitors is inhibited in $L m x 1$ a single and $L m x 1 a / b$ compound mutants at E10.5. The number of Cyclin D2-positive mDA progenitors is reduced in $L m x 1 a$ single and $L m \times 1 a / b$ compound mutants $(\boldsymbol{A}-\boldsymbol{E}, \boldsymbol{K})$. The cyclin-dependent kinase inhibitor p2 $7^{\mathrm{Kip} 1}$ is upregulated $(\boldsymbol{F}-\boldsymbol{J})$ and Wnt1 expression is lost in $L m \times 1 a / b$ double mutants $(\boldsymbol{M}-\boldsymbol{Q})$. The graph in $\boldsymbol{K}$ shows the percentage of Cyclin D2+ cells in mDA domain delineated by $\mathbf{L m x 1 b}$ staining $(\boldsymbol{A}-\boldsymbol{E}$, dotted lines). Quitting fraction (Qf) in the graph in $\boldsymbol{L}$ is obtained after a BrdU pulse at E10.5 and counting the fraction of BrdU-labeled cells at E11.5 that have exited the cell cycle (Brdu+Ki67-Lmx1b+/BrdU+Ki67+Lmx1b+). ${ }^{*} p<0.05$; ${ }^{* *} p<0.01 ;{ }^{* *} p<0.001$; N.S., not significant. Error bars indicate SEM. Scale bars, $100 \mu \mathrm{m}$. 


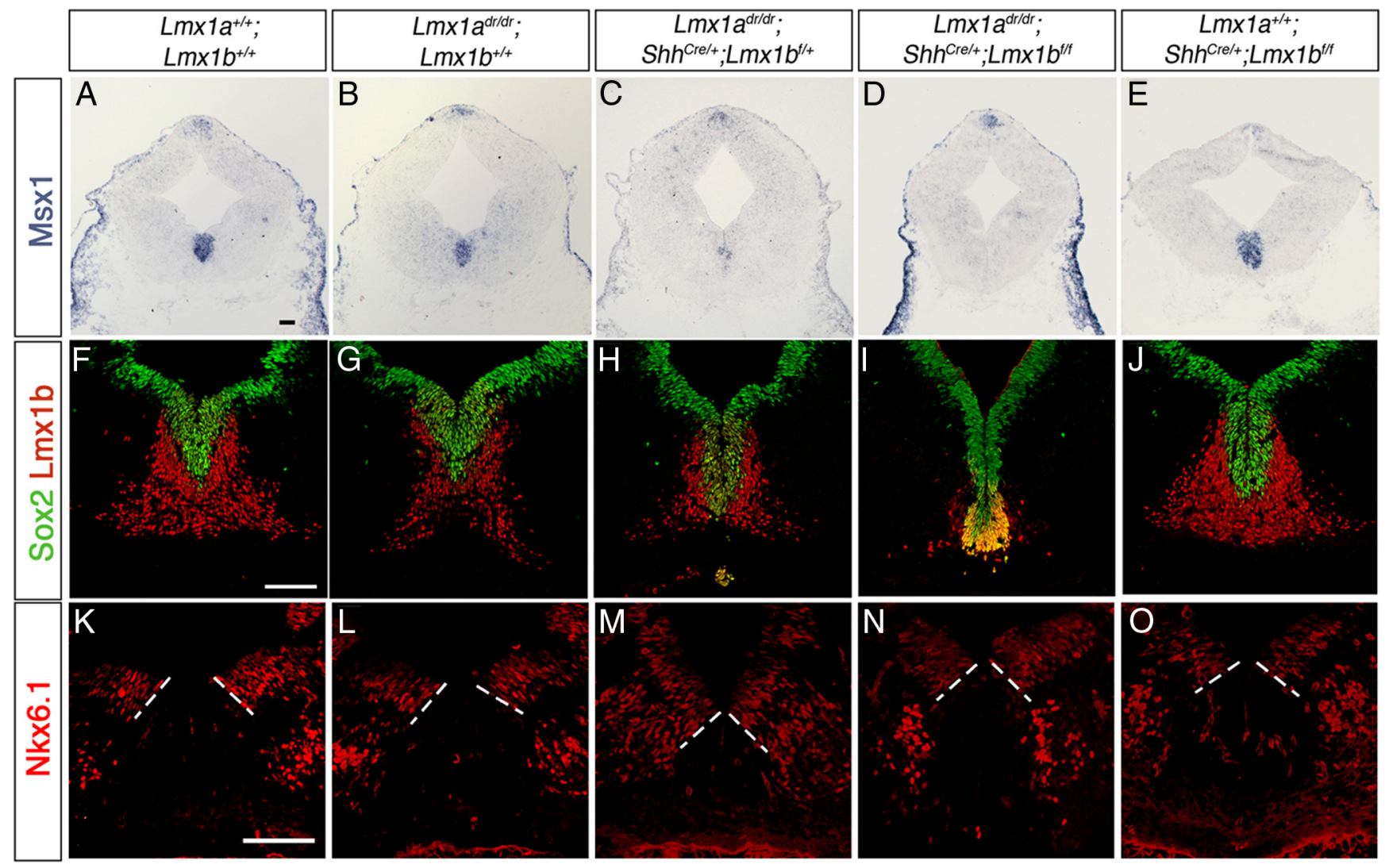

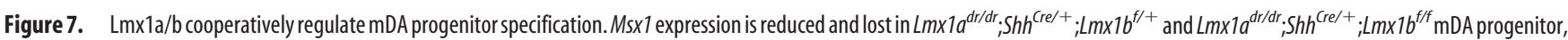
respectively, at E12.5 (A-E). Lmx1b failed to be downregulated in $L m \times 1 a^{d r / d r} ; S h h^{C r e /+} ; L m \times 1 b^{f / f}$ mutant $(\boldsymbol{I})$, whereas Sox2 expression appears normal $(\boldsymbol{F}-J)$. Nkx6.1 expression remains unchanged in all mutant embryos $(\boldsymbol{K}-\mathbf{0})$. The dotted lines correspond to mDA domain delimited by Lmx1a. Scale bars, $100 \mu \mathrm{m}$.

Ngn2 expression in mDA progenitors was observed in NestinHes1 transgenic mouse embryos at E12.5 (Ono et al., 2010).

\section{$\mathrm{Lmxla/b}$ are required for the specification and differentiation} of postmitotic mDA neurons

Previous studies from phenotypic analyses or $\operatorname{Lm} \times 1 a^{d r / d r}$ mutant embryos have shown that Lmxla is also required for the correct differentiation of mDA progenitors by suppressing Lim1/2 expression in postmitotic mDA precursors. We therefore analyzed Lim1/2 expression in Lmxla and Lmx1b single and double mutants. Lim1/2 (also known as Lhx1/5; Mouse Genome Informatics), which are normally expressed in red nucleus neurons lacking Lmx1b expression, were coexpressed with some Lmx1b+ neurons emerging near the margin of the mDA domain of $L m \times 1 a^{d r / d r}$ mutants as previously described and also within the mDA domain of $L m \times 1 a^{d r / d r} ; S_{h h}^{C r e /+} ; L m \times 1 b^{f /+}$ and $L m \times 1 a^{d r / d r} ; S_{S h}{ }^{C r e /+}$; $L m \times 1 b^{f / f}$ embryos (Fig. 10A-E). These Lim $1 / 2+, \operatorname{Lmx} 1 \mathrm{~b}+$ neurons also expressed Lmxla, confirming that they correspond to postmitotic mDA precursors (data not shown). The number of Lmxla + neurons misexpressing Lim $1 / 2$ increased with decreasing number of alleles of Lmxla/b, indicating that Lmxla and Lmx1b function cooperatively to repress Lim $1 / 2$ expression in mDA neurons. We obtained similar results with the red nucleus marker Brn3a, which was also coexpressed by Lmx1b + cells in the mDA domain margin in Lmxla single and Lmxla/b compound mutants (Fig. $10 \mathrm{~K}-\mathrm{O}$ ). Together, these data indicate that Lmxla and Lmxlb also function cooperatively to specify postmitotic mDA precursors. We also found that the expression of Islet $1+$ in oculomotor neurons was similar among all mutants and wild-type embryos (Fig. $10 F-J$ ), indicating that Lmxla and $\mathrm{Lmx} 1 \mathrm{~b}$ are not required for the generation of these neurons from E9.5 onwards.

\section{Discussion}

Lmxlb is not required for the specification and differentiation of $\mathrm{mDA}$ neurons

Lmxlb is expressed in the isthmic organizer and mDA progenitors at E9.5. Previous studies have shown that severe reduction of mDA neurons occurs in $L m x 1 b$-null mutant embryos (Smidt et al., 2000). This loss is primarily due to an earlier role of Lmx1b in regulating the expression of Fgf8 and Wnt1 in the isthmic organizer (Guo et al., 2007). In our paper, Lmxlb is specifically inactivated in mDA progenitors and not in the isthmus in $\mathrm{Shh}^{\mathrm{Cre} /+}$; $L m \times 1 b^{f / f}$ embryos. Specification and differentiation of $\mathrm{mDA}$ progenitors occurred normally in these mutants, indicating that Lmxlb is not required for either of these processes. Lack of a phenotype results from compensation by Lmxla, since double homozygous $L m \times 1 a / b$ mutants show almost complete loss of mDA neurons.

\section{Similar roles for $\mathrm{Lmx} 1 \mathrm{a}$ and $\mathrm{Lmx} 1 \mathrm{~b}$ in regulating} proliferation and differentiation of $\mathrm{mDA}$ progenitors

Lmxla and $L m \times 1 b$ double mutants showed a progressively greater loss in the number of $\mathrm{mDA}$ progenitors compared with Lmxla single mutants (Andersson et al., 2006a; Ono et al., 2007), with the further removal of one and two copies of $L m \times 1 b$ genes. As the percentage of $\mathrm{mDA}$ progenitors in S-phase was proportionately decreased in mutant embryos lacking more copies of 


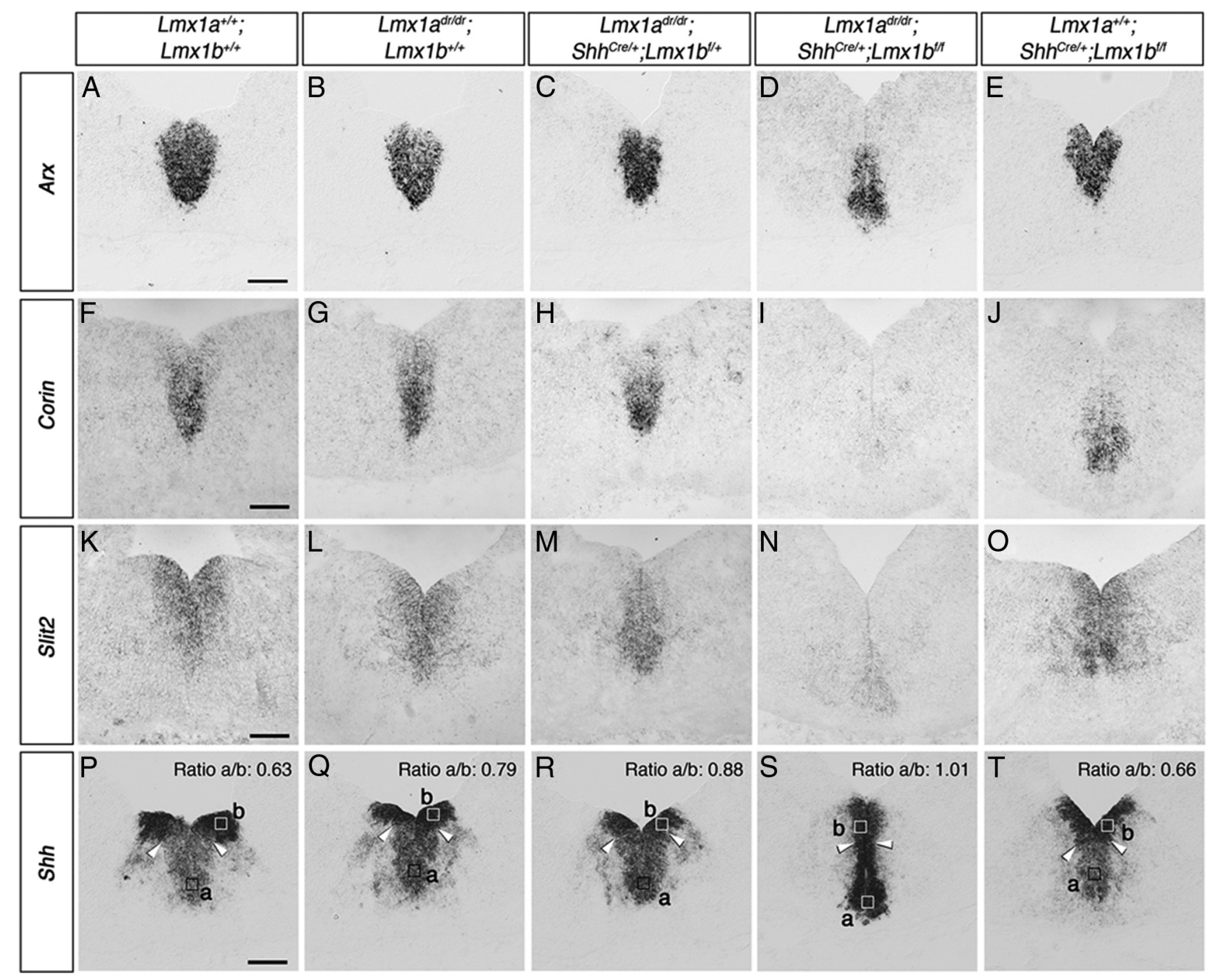

Figure 8. Lmx1a/b regulate midbrain floor plate identity. Expression of floor plate markers, $\operatorname{Arx}(\boldsymbol{A}-\boldsymbol{E})$, Corin $(\boldsymbol{F}-\boldsymbol{J})$, Slit2 $(\boldsymbol{K}-\mathbf{0})$, and $\operatorname{Shh}(\boldsymbol{P}-\boldsymbol{T})$ in midbrain coronal sections at E12.5. The arrowheads indicate dorsal position of floor plate in $\boldsymbol{P}-\boldsymbol{T}$ based on the dorsal limit of Arx expression in corresponding $\boldsymbol{A}-\boldsymbol{E}$. ImageJ software is used to quantify $S h h$ expression between these two regions. Expression ratio is obtained by dividing the mean intensity value from boxed area $\boldsymbol{a}$ by the mean intensity value in boxed area $\boldsymbol{b}$. Note that $\mathrm{Shh}$ expression in $\boldsymbol{S}$ is high in both basal and floor plate progenitors. Scale bar, $100 \mu \mathrm{m}$.

$L m x 1 a$ and $L m x 1 b$ genes, Lmxla and Lmxlb function cooperatively to regulate the number of $\mathrm{mDA}$ progenitors. In addition, $\mathrm{p} 27^{\mathrm{Kip} 1}$ expression was increased in $\mathrm{mDA}$ progenitors and this was accompanied by an increase in the frequency of progenitors exiting cell cycle in $L m \times 1 a^{d r / d r} ; S h h^{C r e /+} ; L m \times 1 b^{f / f}$ embryos at E10.5. None of the other $\operatorname{Lmx} 1 \mathrm{a} / \mathrm{b}$ mutants showed change in $\mathrm{p} 27^{\mathrm{Kip} 1}$ expression and frequency of quitting fraction of progenitors. Together, these results indicate that $\mathrm{Lmxla} / \mathrm{b}$ function cooperatively to regulate the proliferation of mDA progenitors and cell cycle exit.

Lmxla and Lmx1b regulate proliferation of $\mathrm{mDA}$ progenitors in part through the regulation of Wntl that is involved in promoting proliferation of $\mathrm{mDA}$ progenitors (Panhuysen et al., 2004). Consistent with this idea, we show that expression of Cyclin D2, a downstream target of Wnt1 and a major cell cycle regulator (Rulifson et al., 2007), is also severely affected in mutants lacking both $\operatorname{Lmx} 1 a / b$ genes. These results are consistent with the observation that Wnt 1 and Lmxla mutually regulate the expression of each other during differentiation of mouse ES cells into mDA neurons (Chung et al., 2009).
Lmxla and Lmxlb also regulate mDA neuronal cell number by controlling the extent of neurogenesis via regulating the expression of Ngn2. This conclusion is supported by the observation that there is a further decrease in the expression of Ngn2 in mDA progenitors by reducing Lmxlb gene copy number in an Lmxla mutant background. Previous studies have suggested that Lmxla regulate Ngn2 expression (Ono et al., 2007; Nakatani et al., 2010) indirectly, via Msxl genes (Andersson et al., 2006a). Consistent with this hypothesis, Msxl expression was also lost in Lmxla/b double mutants. Our studies also reveal a novel role for $\mathrm{Lmxla/b}$ in regulating neurogenesis via repression of Hes1, a negative regulator of Ngn2. Ectopic Hes1 expression may also explain induction of $\mathrm{p} 27^{\mathrm{Kip} 1}$ expression in $\mathrm{mDA}$ progenitors, as Hes 1 has been shown to induce $\mathrm{p} 27^{\mathrm{Kip} 1}$ in the mDA progenitor domain of Nestin:Hes1 transgenic embryos (Ono et al., 2010).

In conclusion, $\mathrm{Lmxla} / \mathrm{b}$ regulate mDA neuronal cell number by regulating proliferation, cell cycle exit, and differentiation of mDA progenitors. It is noteworthy that the proliferative defect of mDA progenitors in the $\operatorname{Lmx} 1 a / b$ double mutants is similar to that of $E n 1^{C r e} ; O t x 2^{\text {flox/flox }}$ embryos; however, in the latter mutant 


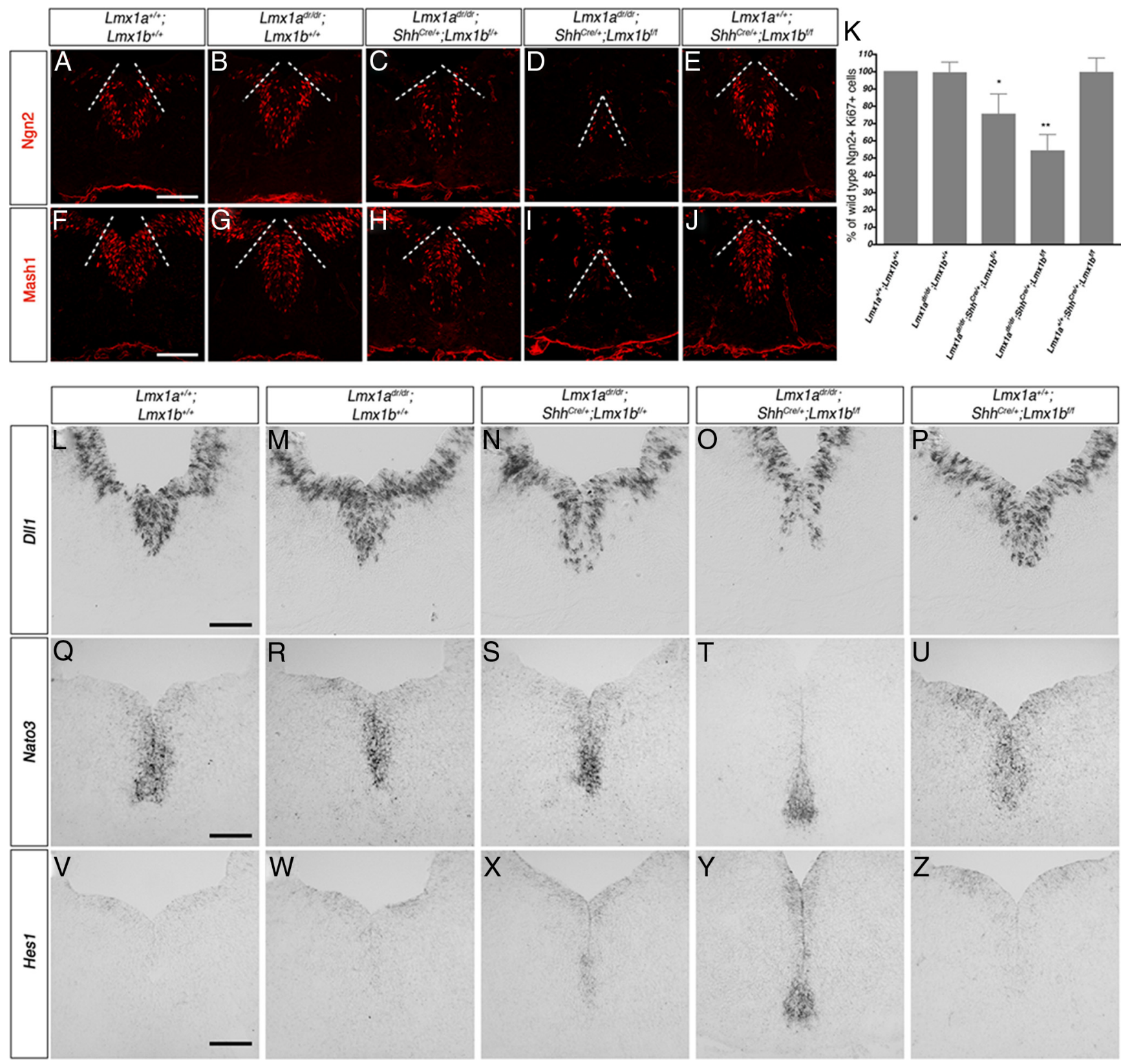

Figure 9. Lmx1a/b regulate neurogenesis of mDA progenitors. Ngn2 and Mash1 expression are reduced in $L m \times 1 a^{d r / d r} ; S h h^{C r e /+} ; \operatorname{Lm} x 1 b^{f /+}$ and $L m \times 1 a^{d r / d r} ; S h h^{C r e /+} ; L m \times 1 b^{f / f} \mathrm{mutant}$ embryos at

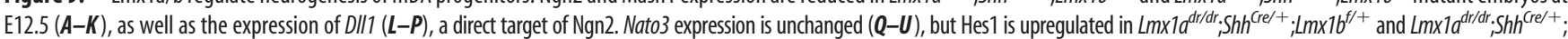
$\mathbf{L m} \times 1 b^{f / f}$ mutant embryos $(\boldsymbol{V}-\boldsymbol{Z})$. Cell counts in the graph in $\boldsymbol{K}$ are done by calculating the fraction of $\mathrm{Ngn} 2+$ Ki67 + double-positive cells over the Ki67+ positive cells within the $\mathrm{mDA}$ progenitor domain delineated by Lmx1a-stained cells. Data are represented as percentage of wild-type littermate numbers. ${ }^{*} p<0.05$; ${ }^{* *} p<0.01$. Error bars indicate SEM. Scale bars, $100 \mu \mathrm{m}$.

embryos, Lmxla expression is lost while Lmxlb is still expressed in $\mathrm{mDA}$ progenitors, and therefore one might have expected a weaker phenotype that is similar to the Lmxla single-mutant phenotype (Omodei et al., 2008). The severe loss of mDA neurons in $E n 1^{\text {Cre }} ; O t x 2^{\text {flox/flox }}$ embryos suggests that Otx2 regulate proliferation in part through regulation of Lmxla and also through regulating Wnt1 independently of Lmxla and Lmx1b since Wnt 1 expression is also lost in En1 $1^{\text {Cre }} ;$ Ot $x 2^{\text {flox/flox }}$ embryos.

\section{Lmxla/b function cooperatively to specify postmitotic mDA neurons}

Earlier studies demonstrate that Lmxla is required for the repression of Lim1/2 expression in postmitotic mDA precursors (Ono et al., 2007). Lmx1b cooperates with Lmxla in repressing Lim $1 / 2$ expression since the number of mDA precursors abnormally expressing Lim $1 / 2$ is increased in $L m \times 1 a / b$ double mutants. Repression of Brn3a in some mDA neurons is also regulated by Lmxla/b. Together, these results indicate that Lmxla/b function cooperatively to regulate specification of postmitotic mDA precursors by inhibiting the expression of determinants of red nucleus neurons in these cells.

\section{Lmxla/b contribute to floor plate differentiation}

Lmxla/b are required to positively regulate both Corin and Slit2, but not Arx expression in mDA progenitors at E12.5. Furthermore, the level of Shh expression was also altered in the midbrain floor plate region of double mutants. These results therefore indicate that $\operatorname{Lmxla} / \mathrm{b}$ are required for floor 


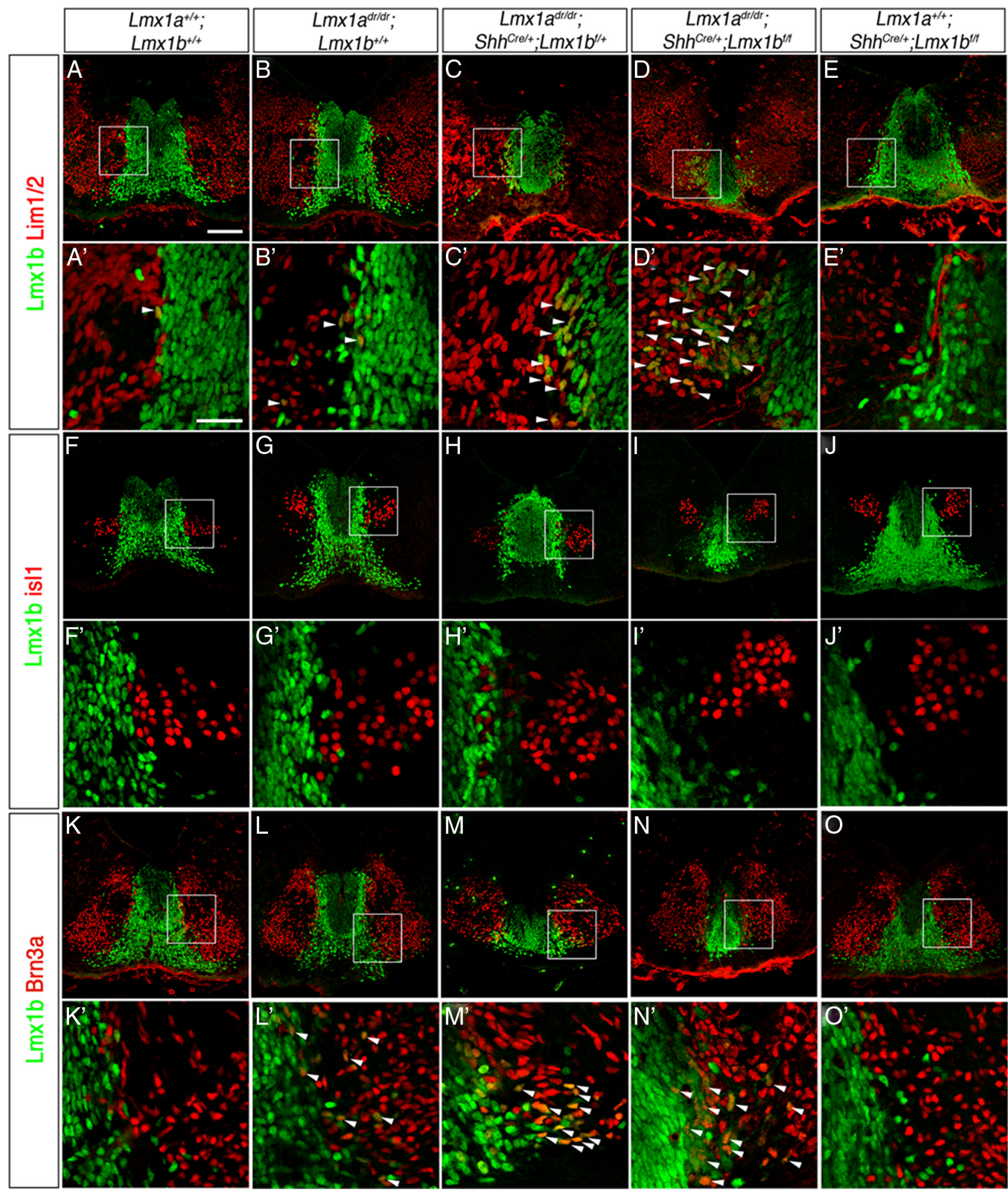

Figure 10. $L m \times 1 a / b$ are required for the specification of postmitotic $m D A$ precursors. Scattered $\operatorname{Lm} x 1 b+$ neurons misexpressing the red nucleus neuron markers $\operatorname{Lim} 1 / 2\left(\boldsymbol{A}-\boldsymbol{E}, \boldsymbol{A}^{\prime}-\boldsymbol{E}^{\prime}\right)$ and $\operatorname{Brn} 3 \mathrm{a}$ $\left(\boldsymbol{K}-\mathbf{O}, \boldsymbol{K}^{\prime}-\mathbf{O}^{\prime}\right)$ are found at the margin of mDA domain in $\mathrm{Lmx1}$ a single and $\mathrm{Lmx} 1 \mathrm{a} / \mathrm{b}$ compound mutant embryos at E12.5. The oculomotor neuron marker Isl-1 does not colocalizes with $\mathrm{Lmx} 1 \mathrm{~b}+$ neurons in any $\mathrm{Lmx} 1 \mathrm{a} / \mathrm{b}$ mutants $\left(\boldsymbol{F}-\boldsymbol{J}, \boldsymbol{F}^{\prime}-\boldsymbol{J}^{\prime}\right)$. Zones delimited by the white squares correspond to the high magnification in $\boldsymbol{A}^{\prime}-\boldsymbol{O}^{\prime}$. The white arrowheads indicate double-labeled neurons. Scale bars: $A, 100 \mu \mathrm{m} ; A^{\prime}, 500 \mu \mathrm{m}$

plate differentiation and are consistent with earlier studies showing that ectopic expression of Lmxla in transgenic mouse embryos can induce Corin and repress Shh expression in basal midbrain progenitors (Nakatani et al., 2010). Slit2 is an axon guidance molecule that has previously shown to regulate the position of ascending dopaminergic fibers projecting into the forebrain (Bagri et al., 2002, Dugan et al., 2011). Together, these findings indicate that Lmxla/b may be involved in regulating axon 
targeting of mDA neurons through regulating the expression of Slit2 in the floor plate.

\section{Concluding remarks}

Our data from loss-of-function studies of $L m \times 1 a / b$ doublemutant mouse embryos demonstrate that these genes function cooperatively to regulate proliferation, specification, and differentiation of mDA progenitors. Interestingly, loss of Lmxla/b did not lead to transformation of mDA progenitor to a more dorsal midbrain progenitor identity, as has been observed in conditional Foxa1 and Foxa2 double mutants. The remaining mDA progenitors continue to express Lmxla and Lmxlb nonfunctional transcripts, a floor plate marker Arx, and did not express the basal progenitor determinant Nkx6.1. However, Lmxla/b regulate Ngn2 expression by activating Msx1 expression, repression of Hes1, and downregulation of Shh, and therefore are required for mDA progenitors to acquire neurogenic potential. Our results also show that $\mathrm{Lmxlb}$ is required for the generation of mDA neurons in mammalian embryos in the absence of Lmxla activity, in contrast to results from loss-of-function studies using gene knockdown approaches in chick embryos. In addition, Lmxla/b are required for Wntl expression and contribute to the regulation of mDA progenitor number in mouse embryos. Lmxla and Lmx1b also cooperate to regulate the expression of Corin and Slit 2 in mDA progenitors. Given the role of $\mathrm{Lmx} 1 \mathrm{a} / \mathrm{b}$ in regulating proliferation and differentiation of $\mathrm{mDA}$ progenitors, the challenge in the future is to understand how Lmxla/b coordinate these two processes to generate the precise number of functional mature $\mathrm{mDA}$ neurons.

\section{References}

Andersson E, Tryggvason U, Deng Q, Friling S, Alekseenko Z, Robert B, Perlmann T, Ericson J (2006a) Identification of intrinsic determinants of midbrain dopamine neurons. Cell 124:393-405.

Andersson E, Jensen JB, Parmar M, Guillemot F, Björklund A (2006b) Development of the mesencephalic dopaminergic neuron system is compromised in the absence of neurogenin 2. Development 133:507-516.

Bagri A, Marín O, Plump AS, Mak J, Pleasure SJ, Rubenstein JL, TessierLavigne M (2002) Slit proteins prevent midline crossing and determine the dorsoventral position of major axonal pathways in the mammalian forebrain. Neuron 33:233-248.

Bettenhausen B, Hrabě de Angelis M, Simon D, Guénet JL, Gossler A (1995) Transient and restricted expression during mouse embryogenesis of Dll1, a murine gene closely related to Drosophila Delta. Development 121:2407-2418

Bjorklund A, Lindvall O (1984) Dopamine-containing systems in the CNS. In: Handbook of chemical neuroanatomy. Amsterdam: Elsevier.

Castelo-Branco G, Rawal N, Arenas E (2004) GSK-3beta inhibition/betacatenin stabilization in ventral midbrain precursors increases differentiation into dopamine neurons. J Cell Sci 117:5731-5737.

Chen H, Lun Y, Ovchinnikov D, Kokubo H, Oberg KC, Pepicelli CV, Gan L, Lee B, Johnson RL (1998) Limb and kidney defects in Lmxlb mutant mice suggest an involvement of LMX1B in human nail patella syndrome. Nat Genet 19:51-55.

Chizhikov VV, Lindgren AG, Currle DS, Rose MF, Monuki ES, Millen KJ (2006a) The roof plate regulates cerebellar cell-type specification and proliferation. Development 133:2793-2804.

Chizhikov V, Steshina E, Roberts R, Ilkin Y, Washburn L, Millen KJ (2006b) Molecular definition of an allelic series of mutations disrupting the mouse Lmxla (dreher) gene. Mamm Genome 17:1025-1032.

Chotteau-Lelièvre A, Desbiens X, Pelczar H, Defossez PA, de Launoit Y (1997) Differential expression patterns of the PEA3 group transcription factors through murine embryonic development. Oncogene 15:937-952.

Chung S, Leung A, Han BS, Chang MY, Moon JI, Kim CH, Hong S, Pruszak J, Isacson O, Kim KS (2009) Wnt1-lmxla forms a novel autoregulatory loop and controls midbrain dopaminergic differentiation synergistically with the SHH-FoxA2 pathway. Cell Stem Cell 5:646-658.

Colombo E, Galli R, Cossu G, Gécz J, Broccoli V (2004) Mouse orthologue of ARX, a gene mutated in several X-linked forms of mental retardation and epilepsy, is a marker of adult neural stem cells and forebrain GABAergic neurons. Dev Dyn 231:631-639.

Conlon RA, Herrmann BG (1993) Detection of messenger RNA by in situ hybridization to postimplantation embryo whole mounts. Methods Enzymol 225:373-383.

Crossley PH, Martin GR (1995) The mouse Fgf8 gene encodes a family of polypeptides and is expressed in regions that direct outgrowth and patterning in the developing embryo. Development 121:439-451.

Dugan JP, Stratton A, Riley HP, Farmer WT, Mastick GS (2011) Midbrain dopaminergic axons are guided longitudinally through the diencephalon by Slit/Robo signals. Mol Cell Neurosci 46:347-356.

Echelard Y, Epstein DJ, St-Jacques B, Shen L, Mohler J, McMahon JA, McMahon AP (1993) Sonic hedgehog, a member of a family of putative signaling molecules, is implicated in the regulation of CNS polarity. Cell 75:1417-1430.

Farkas LM, Dünker N, Roussa E, Unsicker K, Krieglstein K (2003) Transforming growth factor- $\beta(s)$ are essential for the development of midbrain dopaminergic neurons in vitro and in vivo. J Neurosci 23:5178-5186.

Ferri AL, Lin W, Mavromatakis YE, Wang JC, Sasaki H, Whitsett JA, Ang SL (2007) Foxa1 and Foxa2 regulate multiple phases of midbrain dopaminergic neuron development in a dosage-dependent manner. Development 134:2761-2769.

Guo C, Qiu HY, Huang Y, Chen H, Yang RQ, Chen SD, Johnson RL, Chen ZF, Ding YQ (2007) Lmxlb is essential for Fgf8 and Wntl expression in the isthmic organizer during tectum and cerebellum development in mice. Development 134:317-325.

Harfe BD, Scherz PJ, Nissim S, Tian H, McMahon AP, Tabin CJ (2004) Evidence for an expansion-based temporal Shh gradient in specifying vertebrate digit identities. Cell 118:517-528.

Hobert O, Westphal H (2000) Functions of LIM-homeobox genes. Trends Genet 16:75-83.

Hynes M, Stone DM, Dowd M, Pitts-Meek S, Goddard A, Gurney A, Rosenthal A (1997) Control of cell pattern in the neural tube by the zinc finger transcription factor and oncogene Gli-1. Neuron 19:15-26.

Joksimovic M, Yun BA, Kittappa R, Anderegg AM, Chang WW, Taketo MM, McKay RD, Awatramani RB (2009a) Wnt antagonism of Shh facilitates midbrain floor plate neurogenesis. Nat Neurosci 12:125-131.

Joksimovic M, Anderegg A, Roy A, Campochiaro L, Yun B, Kittappa R, McKay R, Awatramani R (2009b) Spatiotemporally separable Shh domains in the midbrain define distinct dopaminergic progenitor pools. Proc Natl Acad Sci U S A 106:19185-19190.

Kele J, Simplicio N, Ferri AL, Mira H, Guillemot F, Arenas E, Ang SL (2006) Neurogenin 2 is required for the development of ventral midbrain dopaminergic neurons. Development 133:495-505.

Kitamura K, Miura H, Yanazawa M, Miyashita T, Kato K (1997) Expression patterns of Brx1 (Rieg gene), Sonic hedgehog, Nkx2.2, Dlx1 and Arx during zona limitans intrathalamica and embryonic ventral lateral geniculate nuclear formation. Mech Dev 67:83-96.

Kittappa R, Chang WW, Awatramani RB, McKay RD (2007) The foxa2 gene controls the birth and spontaneous degeneration of dopamine neurons in old age. PLoS Biol 5:e325.

Krawchuk D, Kania A (2008) Identification of genes controlled by LMX1B in the developing mouse limb bud. Dev Dyn 237:1183-1192.

Lang AE, Lozano AM (1998) Parkinson's disease. Second of two parts. N Engl J Med 339:1130-1143.

Lin W, Metzakopian E, Mavromatakis YE, Gao N, Balaskas N, Sasaki H, Briscoe J, Whitsett JA, Goulding M, Kaestner KH, Ang SL (2009) Foxal and Foxa2 function both upstream of and cooperatively with Lmxla and Lmx $1 b$ in a feedforward loop promoting mesodiencephalic dopaminergic neuron development. Dev Biol 333:386-396.

Lyons JP, Wahlsten D (1988) Postnatal development of brain and behavior of shaker short-tail mice. Behav Genet 18:35-53.

Marín F, Herrero MT, Vyas S, Puelles L (2005) Ontogeny of tyrosine hydroxylase mRNA expression in mid- and forebrain: neuromeric pattern and novel positive regions. Dev Dyn 234:709-717.

McMahon AP, Bradley A (1990) The Wnt-1 (int-1) proto-oncogene is required for development of a large region of the mouse brain. Cell 62:1073-1085.

Millonig JH, Millen KJ, Hatten ME (2000) The mouse Dreher gene Lmxla controls formation of the roof plate in the vertebrate CNS. Nature 403:764-769. 
Mishima Y, Lindgren AG, Chizhikov VV, Johnson RL, Millen KJ (2009) Overlapping function of Lmxla and Lmxlb in anterior hindbrain roof plate formation and cerebellar growth. J Neurosci 29:11377-11384.

Nakatani T, Kumai M, Mizuhara E, Minaki Y, Ono Y (2010) Lmxla and Lmxlb cooperate with Foxa2 to coordinate the specification of dopaminergic neurons and control of floor plate cell differentiation in the developing mesencephalon. Dev Biol 339:101-113.

Olanow CW, Goetz CG, Kordower JH, Stoessl AJ, Sossi V, Brin MF, Shannon KM, Nauert GM, Perl DP, Godbold J, Freeman TB (2003) A doubleblind controlled trial of bilateral fetal nigral transplantation in Parkinson's disease. Ann Neurol 54:403-414.

Omodei D, Acampora D, Mancuso P, Prakash N, Di Giovannantonio LG, Wurst W, Simeone A (2008) Anterior-posterior graded response to Otx2 controls proliferation and differentiation of dopaminergic progenitors in the ventral mesencephalon. Development 135:3459-3470.

Ono Y, Nakatani T, Sakamoto Y, Mizuhara E, Minaki Y, Kumai M, Hamaguchi A, Nishimura M, Inoue Y, Hayashi H, Takahashi J, Imai T (2007) Differences in neurogenic potential in floor plate cells along an anteroposterior location: midbrain dopaminergic neurons originate from mesencephalic floor plate cells. Development 134:3213-3225.

Ono Y, Nakatani T, Minaki Y, Kumai M (2010) The basic helix-loop-helix transcription factor Nato3 controls neurogenic activity in mesencephalic floor plate cells. Development 137:1897-1906.

Panhuysen M, Vogt Weisenhorn DM, Blanquet V, Brodski C, Heinzmann U, Beisker W, Wurst W (2004) Effects of Wnt1 signaling on proliferation in the developing mid-/hindbrain region. Mol Cell Neurosci 26:101-111.

Prakash N, Brodski C, Naserke T, Puelles E, Gogoi R, Hall A, Panhuysen M, Echevarria D, Sussel L, Weisenhorn DM, Martinez S, Arenas E, Simeone A, Wurst W (2006) A Wnt1-regulated genetic network controls the identity and fate of midbrain-dopaminergic progenitors in vivo. Development 133:89-98.

Puelles E, Acampora D, Lacroix E, Signore M, Annino A, Tuorto F, Filosa S, Corte G, Wurst W, Ang SL, Simeone A (2003) Otx dose-dependent integrated control of antero-posterior and dorso-ventral patterning of midbrain. Nat Neurosci 6:453-460.
Rulifson IC, Karnik SK, Heiser PW, ten Berge D, Chen H, Gu X, Taketo MM, Nusse R, Hebrok M, Kim SK (2007) Wnt signaling regulates pancreatic beta cell proliferation. Proc Natl Acad Sci U S A 104:6247-6252.

Schaeren-Wiemers N, Gerfin-Moser A (1993) A single protocol to detect transcripts of various types and expression levels in neural tissue and cultured cells: in situ hybridization using digoxigenin-labelled cRNA probes. Histochemistry 100:431-440.

Smidt MP, van Schaick HS, Lanctôt C, Tremblay JJ, Cox JJ, van der Kleij AA, Wolterink G, Drouin J, Burbach JP (1997) A homeodomain gene Ptx3 has highly restricted brain expression in mesencephalic dopaminergic neurons. Proc Natl Acad Sci U S A 94:13305-13310.

Smidt MP, Asbreuk CH, Cox JJ, Chen H, Johnson RL, Burbach JP (2000) A second independent pathway for development of mesencephalic dopaminergic neurons requires Lmx1b. Nat Neurosci 3:337-341.

Tang M, Miyamoto Y, Huang EJ (2009) Multiple roles of beta-catenin in controlling the neurogenic niche for midbrain dopamine neurons. Development 136:2027-2038.

Tang M, Villaescusa JC, Luo SX, Guitarte C, Lei S, Miyamoto Y, Taketo MM, Arenas E, Huang EJ (2010) Interactions of Wnt/ $\beta$-catenin signaling and sonic hedgehog regulate the neurogenesis of ventral midbrain dopamine neurons. J Neurosci 30:9280-9291.

Tomita K, Ishibashi M, Nakahara K, Ang SL, Nakanishi S, Guillemot F, Kageyama R (1996) Mammalian hairy and Enhancer of split homolog 1 regulates differentiation of retinal neurons and is essential for eye morphogenesis. Neuron 16:723-734.

Tsuchida T, Ensini M, Morton SB, Baldassare M, Edlund T, Jessell TM, Pfaff SL (1994) Topographic organization of embryonic motor neurons defined by expression of LIM homeobox genes. Cell 79:957-970.

Ye W, Shimamura K, Rubenstein JL, Hynes MA, Rosenthal A (1998) FGF and Shh signals control dopaminergic and serotonergic cell fate in the anterior neural plate. Cell 93:755-766.

Zhao ZQ, Scott M, Chiechio S, Wang JS, Renner KJ, Gereau RW 4th, Johnson RL, Deneris ES, Chen ZF (2006) Lmxlb is required for maintenance of central serotonergic neurons and mice lacking central serotonergic system exhibit normal locomotor activity. J Neurosci 26:12781-12788. 